\title{
Standards required in maintaining the chain of evidence in the context of post rape care services: Findings of a study conducted in Kenya
}

Carol Ajema

Emily Rogena

Hadley Muchela

Buluma Bwire

Nduku Kilonzo

Follow this and additional works at: https://knowledgecommons.popcouncil.org/departments_sbsr-rh

Part of the Demography, Population, and Ecology Commons, Domestic and Intimate Partner Violence Commons, Family, Life Course, and Society Commons, Gender and Sexuality Commons, International Public Health Commons, Medicine and Health Commons, and the Women's Health Commons How does access to this work benefit you? Let us know!

\section{Recommended Citation}

Ajema, Carol, Emily Rogena, Hadley Muchela, Buluma Bwire, and Nduku Kilonzo. 2009. "Standards required in maintaining the chain of evidence in the context of post rape care services: Findings of a study conducted in Kenya." Nairobi: Liverpool VCT, Care \& Treatment, the Division of Reproductive Health, and the Population Council. 
Standards required in maintaining the chain of evidence in the context of

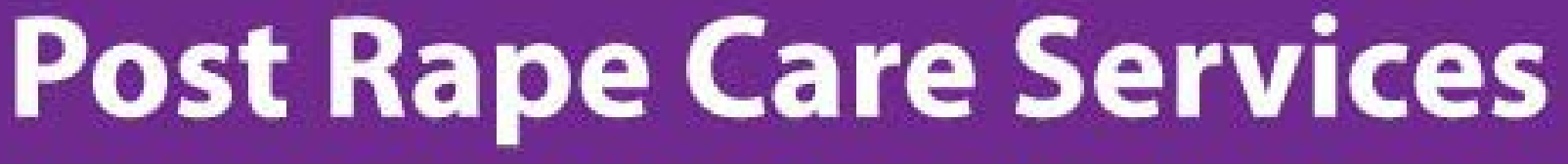

Findings of a study conducted in Kenya

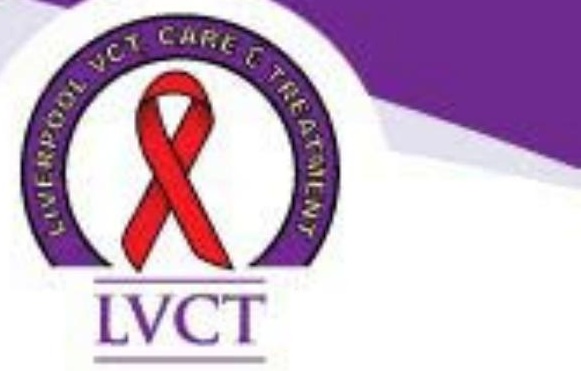




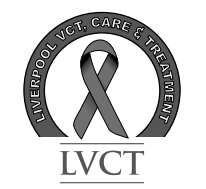

Liverpool VCT,Care \& Treatment(LVCT)

www.liverpoolvct.org

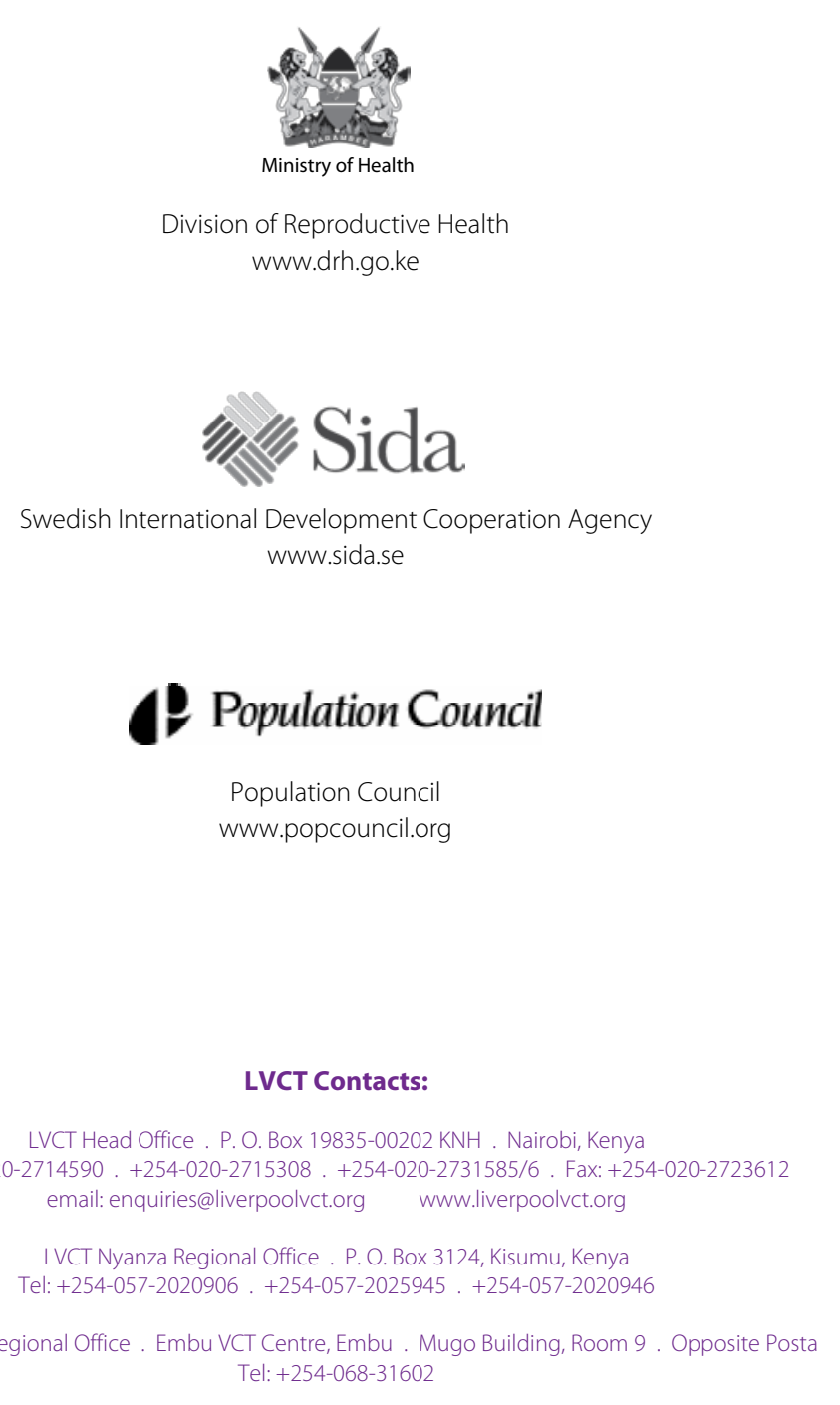

\begin{abstract}
LVCT Eastern Regional Office. Embu VCT Centre, Embu. Mugo Building, Room 9 . Opposite Posta
Tel: $+254-068-31602$
LVCT Head Office P. O Box 19835-00202 KNH . Nairobi, Kenya

Tel: +254-020-2714590 . +254-020-2715308 . +254-020-2731585/6 . Fax:+254-020-2723612

email: enquiries@liverpoolvct.org www.liverpoolvct.org

LVCT Nyanza Regional Office . P. O. Box 3124, Kisumu, Kenya

Tel: +254-057-2020906 +254-057-2025945 + +254-057-2020946
\end{abstract}

\title{
To be cited as:
}

Ajema, C., Rogena, E., Muchela, H., Buluma, B. and Kilonzo, N. 2009. 
Standards required in maintaining the chain of evidence in the context of post rape care services:

Findings of a study conducted in Kenya

Report By:

Carolyne Ajema

Buluma Bwire 


\section{CONTENTS}

List of Tables

Acronyms

Acknowledgements. $v i$

Operational Definitions.

Executive Summary

B A C K G R O U D 1

Sectoral responses to SV in Kenya

Evidence chain maintenance in Kenya

Maintenance of the evidence chain: Gaps in the responses made within the Kenyan context .3

METHODS 5

Objectives

Design.

Study sample and data collection methods .5

Ethical considerations 6

Data management and analysis . .7

Limitations of the study. .7 
Type of evidence collected

Who collects the evidence

Tools used to collect samples

Documentation

Challenges at community level

CONCLUSIONS AND RECOMMENDATIONS

\section{A N NEXES}




\section{LIST OF TABLES}

Table 1: Study respondents at baseline and endline

Table 2: Rape kit content list

Table 3: Types of samples collected at baseline and endline.

\section{LIST OF FIGURES}

Figure 1: Gaps in evidence collected as indicated on the PRC 1 form 


\begin{tabular}{|c|c|}
\hline CCC & Comprehensive Care Clinics \\
\hline CJS & Criminal Justice System \\
\hline DHMT & District Health Management Team \\
\hline DNA & Deoxyribonucleic Acid \\
\hline DRH & Division of Reproductive Health \\
\hline EC & Emergency Contraception \\
\hline GBV & Gender Based Violence \\
\hline HCW & Health Care Worker \\
\hline HIV & Human Immunodeficiency Virus \\
\hline LVCT & Liverpool VCT, Care and Treatment \\
\hline OPD & Out Patient Department \\
\hline P3 & Kenya Police Medical Examination Form \\
\hline PEP & Post Exposure Prophylaxis \\
\hline PRC & Post Rape Care \\
\hline PRC 1 & Post Rape Care 1 Form \\
\hline SDP & Service Delivery Point \\
\hline STI & Sexually Transmitted Infections \\
\hline SV & Sexual Violence \\
\hline WHO & World Health Organization \\
\hline
\end{tabular}




\section{ACKNOWLEDGEMENTS}

The actualization of this study was made possible through funding generously contributed by the Swedish International Development Cooperation Agency (SIDA) channelled through the auspices of Population Council, Kenya.

Appreciation goes to Dr. Nduku Kilonzo, Dr. Emily Rogena, Dr. Margaret Meme, and Mr. Hadley Muchela who together with the authors of this report conceptualized the study.

The Division of Reproductive Health within the Ministry of Public Health and Sanitation, The Medical Officers of Health and the District AIDS/STI Coordinators of the 2 selected District Hospitals, The Government Chemist department, The Nyanza and Eastern Provinces Police Administration, and The Community leaders from the 2 study districts are much appreciated.

Gratitude is also expressed to the LVCT staff and especially the Research team; Serah Nduta, Mary Valai, Juliana Akinyi, Ndindi Mutisya, Inviolata Njeri, Brenda Metobo, Alfred Otieno, Anita Gakii, Christina Njambi, Paul Kiarie, Hawa Ngari, Gloria Khisa, Elizabeth Njoki and Patrick Angala who were involved in the development of study tools, data collection, coding, and analysis. We also recognise the immense effort made by Dr. Jill Keesbury of Population Council to review the report.

Thanks also to the Post Rape Care team: Hadley Muchela, Rukia Yassin, Purity Kajuju, Charity Mbugua, Pauline Obop, and John Mungai from the Government Chemist's Department who greatly assisted in the trainings of stakeholders from the health facilities, police, and community during the intervention phase of the study.

We specifically appreciate the respondents whose participation greatly shaped the fruitful outcome of this study. 


\section{OPERATIONAL DEFINITIONS}

Adult:

Chain of Evidence:

Children:

Forensic Examination:

Medico-Legal Evidence: for legal purposes'. It includes biological samples, non-biological specimens, extra-genital and ano-genital injuries, and the emotional state of the survivor at the time of the forensic examination. This term is also used herein to refer to forensic evidence.

P3 Form:

Protocols:

Samples/Specimens:

Sexual Violence:

Survivors:

Traditional Courts:
Refer to the established and documented procedures for maintaining the chain of evidence in cases of sexual violence.

It is a legal document (also referred to as the Kenya Police Medical Examination Form) found in police stations that doctors fill in during examination of rape survivors and is used as medical evidence during investigation and prosecution processes to prove, corroborate or at times disprove the occurrence of the incident of sexual violence.

These terms are used synonymously to refer to any evidence that is retrieved from the survivors of sexual violence.

"Is any sexual act, attempt to obtain a sexual act, unwanted sexual comments or advances, or acts to traffic a person's sexuality, using coercion, threats of harm or physical force, by any person regardless of relationship to the victim, in any setting including but not limited to home and work.

Refers to persons who have been sexually assaulted.

These refer to the different systems that exist in the communities that act as arbitrators of disputes that arise within its members. 


\section{EXECUTIVE SUMMARY}

\section{Background}

Sexual violence remains a public health problem and human rights violation. Various strategies have been formulated and put in place that inform the standards of care to be considered while offering medical and legal services to survivors of sexual violence. Appropriate management of survivors of sexual violence requires a standardized clinical evaluation, and an effective interface with law enforcement for the handling of forensic evidence, and coordination of the continuum of care. Despite this, there lacks an implementation framework clearly outlining the role of the survivor (or wider community), health care workers and the police with regard to handling evidence post assault.

\section{Objectives}

In 2007, Liverpool VCT, Care \& Treatment carried out an operations research study whose objectives were: (1) To describe the current practices and gaps in the collection, storage, analysis, documentation and transportation of evidence collected from survivors at the hospitals and police stations in the context of sexual violence; (2) To design and test an evidence chain model applicable to the Kenyan system for obtaining and transporting samples from the primary health facilities to the government chemist; and (3) To evaluate the model developed for functional custody of evidence chain suited for the Kenyan context.

\section{Methodology}

The study was an operations research carried out in 2007/8 using the exploratory design with data being collected from $\mathbf{2}$ hospitals and $\mathbf{2}$ police stations in Nyanza and Eastern provinces (both institutions hereafter referred to as sites). These sites were selected because the health facilities in these regions had been involved in the provision of Post Rape Care services as from 2004, and the police had been sensitised on the delivery of services to survivors of sexual violence who present at the police stations. A total of 29 respondents were interviewed at baseline and 24 at end line. Purposive sampling was utilised in selecting the respondents. Qualitative data were recorded and transcribed then analyzed based on the emerging themes using NVivo 8 software. Data were also captured from the hospital records through photocopying and analyzed using Epi Info 7. Ethics approval to conduct this study was obtained from the Kenyatta National Hospital Ethics Review Board, whereas permission to interview the respondents and review records was obtained from the management of the health facilities and police stations. Informed consent was then obtained from the respondents who agreed to participate in the study. 


\section{Summary of Key findings}

\section{Type of evidence collected}

The data from baseline showed that emphasis was placed on collecting high vaginal swab (HVS), blood and urine samples from the survivors. The HVS was used to check if there was any spermatozoa present; urine for carrying out a pregnancy test and blood for the purpose of checking haemoglobin levels. At the end-line stage, respondents from both district health facilities and police stations indicated diversity in the type of samples that were being retrieved from survivors of sexual violence at baseline and at end-line. These differences in the type of samples collected in the intervention site after the baseline phase could be attributed to the trainings that were conducted among the health care providers and police personnel. The study established that it is only the health care providers who collect evidence, since the Police indicated their reliance on the medical evidence obtained at the health facility.

\section{Tools Used in evidence collection}

Through the study it was realised that despite the stipulations within the national guidelines on the management of sexual violence that HCWs should ensure that the required medico-legal evidence is collected from all survivors, it was established that there were instances where the equipments required in facilitating this process were not adequate. Majority of the HCWs indicated their capacity gaps in using the available tools, for example, the speculum in drawing samples from children.

\section{Documentation}

At baseline it was established that health care workers were not using the PRC1 forms to record details of all the survivors of sexual violence who were presenting at the two health facilities. Quantitative data collected from the hospital records at baseline was not analyzed due to the inconsistencies in documentation and also use of the generic term "assault" in cases of SV without clearly indicating the type of offence reported. There were also variations in the type of documents maintained for survivors who presented at the health facilities. This situation was however different at the end-line phase as both sites targeted during this study reported an improvement in the level and content of documentation of cases of SV.

\section{Storage and analysis of evidence}

It was established at both baseline and end-line phases of the project that all the medical samples collected by the health care workers were analysed within the hospital laboratory. However the health care workers continued to experience challenges in the storage of forensic evidence collected due to lack of storage facilities that would enhance integrity of the samples collected. It was also established that the police do not store evidence at the police stations, but instead leave it at the health facility till when the case is brought up for hearing in the courts. 


\section{Community Involvement}

Delayed presentation of survivors of SV to either the police station or health facility was found to be a major inhibitor to the collection of required medico-legal evidence from survivors. These delays were also found to be a source of frustration among the health care workers who indicated their lack of knowledge on the type of evidence to be collected from survivors who present long after the violation.

\section{Management of Children}

Despite literature indicating that majority of survivors are children, the study brought to the fore the fact that most providers lack the required skill in handling children, with a focus on collection of evidence. Some of the contributing factors included: lack of trust by the children, among others.

\section{Conclusion and Recommendation}

Overall results show that proper documentation is the most effective way of capturing details on survivors of SV as well as maintaining the custody of evidence chain in cases of SV. This can be achieved through the review of existing protocols and/or development of protocols that clearly stipulate what is the minimum evidence that should be collected from survivors of SV; what is the first point of presentation of survivors of SV; who should collect evidence; and what should be used in documenting evidence obtained from survivors. There is also need to review the existing medico-legal documentation, namely, the PRC1 forms to ensure the maintenance of a proper paper trail of evidence collected from survivors. 


\section{B A C K G R O U N D}

Sexual violence (SV) is a serious societal problem that creates significant challenges to local communities in their attempt to create an overall plan for meeting medical, emotional, physical safety, and legal needs of a survivor of SVii. Issues of sexual violence cannot be addressed in a vacuum. It is important to understand and recognize the existing links between the health sector and police as a basis to address the complexities surrounding SViii,iv. Appropriate management of survivors of SV requires a standardized clinical evaluation, an effective interface with law enforcement for the handling of forensic evidence, and coordination of the continuum of carev.

The effects of SV cut across aspects of public health and human rights as applied to the survivor(s) of SV. From the public health perspective, the issues to be addressed revolve around accessibility of the medical services and consistency in the quality of care. The public health concerns are also guided by the legal procedures to be observed in the collection of medico-legal evidence by the health care providers from the survivor to be used in prosecution of the sexual offenders within the Criminal Justice System (CJS). Hence the need for different countries to clearly develop standardised mechanisms through which appropriate medico-legal support will be delivered to survivors of SV from a medical and legal dimension.

\section{Sectoral responses to SV in Kenya}

There are wide responses that have been made by different sectors in Kenya towards addressing sexual violence from a medicolegal perspective.

\section{Health System}

The health sector offers the initial clinical evaluation (forensic examination and documentation), clinical management (provision of Post Exposure Prophylaxis for HIV, Emergency Contraceptives and STI drugs), and counseling to the survivors. Health Care Workers (HCWs) are expected to provide the collected evidence to the justice system. This expectation is to be contrasted with the fact that HCWs who provide care to survivors of SV often lack training in forensic evidence collectionvi. The delivery of PRC services is done from selected service delivery points within the health facilities as determined by the hospital management, for example, the casualty, comprehensive care clinic, and laboratory, among others. This in turn could contribute to a lack of standardised service delivery and referral mechanisms within public hospitals, and from the health facilities to the police stations. In some areas, cost of health services may hinder the poor from accessing care on time because immediate care should be offered within 72 hours post assault for purposes of also ensuring that the required evidence is also collected within the required time limits ${ }^{\text {vii. }}$

\section{Criminal Justice System}

SV has been defined as any sexual act, attempt to obtain a sexual act, unwanted sexual comments or advances, or acts to traffic [a person's] sexuality, using coercion, threats of harm or physical force, by any person regardless of relationship to the victim, in any setting including but not limited to home and work viii. It is thus by its very nature an overt crime, an overt crime being one that involves direct physical or psychological injury to other people. In Kenya various types of SV have been criminalized under the Sexual Offences Act, for example. rape, sexual assault, gang rape, indecent acts with an adult or child, defilement, and incestix. These different types of sexual offences have been clearly defined in the Kenya Sexual Offences Act, 2006. 
Rape and all types of sexual offences in Kenya are considered to be crimes against the state. The police are the custodians of evidence collected by HCWs and are the gateway into the criminal justice system for survivors of SV. However, only about $25 \%$ of SV cases prosecuted in court realize convictions due to a myriad of factors for instance poor investigation of cases, which includes failure to preserve evidence and poor handling of crime scenes ${ }^{\mathrm{xi}}$. These often have a negative impact on the successful prosecution of cases. Moreover the police and the government chemist (who analyse the forensic evidence collected) are currently in different ministries and there is limited communication between the two bodies. The police are a crucial component of the post-sexual assault evidentiary process thus they can play the role of either facilitating or barring the collection and processing of the evidence ${ }^{\mathrm{xii}}$. A factor pointing towards the latter role is that survivors who seek police intervention are often embarrassed,

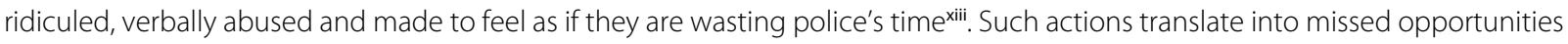
for survivors to access both medical and legal services.

\section{Evidence chain maintenance in Kenya}

The evidence chain is a term used to refer to the process of obtaining, preserving and conveying evidence through accountable tracking mechanisms from the health facility and finally to the police ${ }^{\text {xiv. }}$. The tracking mechanisms in question would include labelling, signing and dating of the evidence by the person who collected them from either the health facility and/or police. Without this documentation, complete with signatures of the chain of custody from the individual who collected the evidence, such evidence is considered inadmissible in court.

There is little literature detailing the requirements on how to maintain the evidence chain within the Kenyan context with established linkages between the health, police, and community. The effect of this is such that:

Although the police follow a standard procedure in cases of SV, there is no manual or handbook detailing protocols to be observed in maintaining the chain of evidence in Kenya.

- The HCWs have expressed some of the challenges they encounter in evidence collection, analysis and documentation. Mainly, the lack of tools and equipment to facilitate evidence retrieval, documentation, storage and transportation of evidence gathered by the examining doctor does not always produce enough details to provide corroborative evidence ${ }^{\mathrm{xv}}$.

The existence of parallel justice systems within communities in the form of 'traditional courts' serve to increase a survivor's vulnerability and medical attention is not given a priority in such systems. Perpetrators are often only asked to pay fines and the survivor in such instances does not get to access both formal medical and legal services.

Maintenance of the evidence chain is the most critical interface between the medical and legal sectors and it is clear that it has been neglected ${ }^{x v i}$. Scant attention is given to examination and documentation of SV, particularly with regard to issues of handling of evidence by HCWs and the police. The lack of national minimum standards on the maintenance of the evidence chain in cases of SV further compounds the problem. This is exacerbated by the lack of a forensic medicine system in Kenya and legal requirements that only doctors can give evidence in an environment where there exists a limited number of doctors who also have a huge workload. 


\section{Maintenance of the evidence chain: Gaps in the responses made within the Kenyan context}

Despite the responses made to address the provision of medico-legal services to survivors of sexual violence, the following gaps

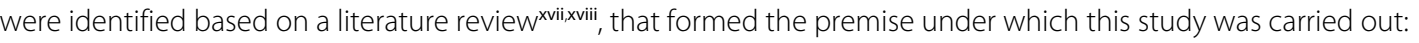

The nature of legislation provides challenges for health sector response.

For example section 36(3) of the Sexual Offences Act (SOA), states that the samples collected by health care providers should be stored in a data bank, but there is only one government chemist facility which is based in Nairobi, the capital city of Kenya. Yet there are no transport/storage systems in place for the evidence collected in other health facilities to be forwarded to this facility. This therefore makes it difficult for the evidence collected at the public health facilities to be subjected to further analysis by the government chemist, and hence not adduced in court as corroborative evidence.

\section{There are challenges in high evidentiary requirements}

The possible samples that can be collected as evidence include: injury evidence, clothing, hair, sperm \& seminal fluid, blood or urine. The medical exam is often flawed and at times doctors who examine survivors provide inaccurate or non-specific information and leave out the most vital information e.g. the nature of assault, description of the physical and mental state of the survivor, the type of samples collected etc. If there is a suspect, police often do not ensure that a doctor examines him for corroboratory evidence, such as a sexually transmitted disease, which is acceptable to the court as evidence. It is not unusual for HCWs to use the Kenya Police Medical Examination Form (otherwise known as the P3 form) which seems to have been tailor made for accident and general assault cases, and is insufficient for recording details of SV. The form also presupposes that all survivors will resist abuse and hence tends to focus on the attire at the point of abuse. P3 forms completed by doctors are often 'lost' by the police and not produced in court. Government doctors are not allowed to keep a copy of the completed P3 form for their records.

\section{Poor linkages between the health system that is expected to provide primary evidence and the criminal justice system who are the custodians of the evidence}

Evidence collected at health facilities cannot be 'paper-trailed' through to its utilization in court, thus there is potential for interference with evidence. Ideally the evidence collected at the hospital should be taken to the police station by the police at the district level and sent to the government chemist in Nairobi for analysis and the results passed back to the district. However most of the samples collected never reach the government chemist due to challenges in transportation, proper storage and lack of effective feedback mechanisms between these levels of facilities.

\section{Law and order sector}

It is up to the state to prove that a survivor has been sexually violated. However, the survivor is still required to supply information in order to support her/his allegation of SV. To obtain this proof, the state is responsible for ensuring that it has the resources to gather medical evidence in line with the national guidelines on the management of survivors of SV. The state must start the process of investigation immediately after the initial allegation by means of a thorough medico-legal examination and proper 
preservation of evidence, so that all necessary evidence is obtained and available to the courts when the case is heard. There however, lacks a specialization and sensitization protocol of police investigators and prosecutors on how to handle cases of SV. This makes it impossible to comply with the good practices recommended to service providers in cases of sexual violence.

\section{Community}

The community has a role to play in the maintenance of the evidence chain as it is within its confines that the survivor, perpetrator and the scene of crime are located. However there is lack of knowledge within the community on what needs to be done, this often leads to evidence destruction either through bathing or failing to report, either to hospital or police, on time or even throwing away clothes worn during the assault. Cases of SV are at times addressed by the local tribal courts where perpetrators are required to pay a cash or material fine to the survivor's familyxix. There is, however, no documentation on the role that the community is to play in the maintenance of the evidence chain.

\section{Laboratory standards}

There are no set operational standards for proper maintenance of evidence collected from survivors of sexual violence. The causes alluded to as reasons for this gap include: lack of clear protocols for collection, preservation and analysis of specimen and evidence collected within health facilities, lack of systems for the management and utilization of results from the limited specimen that get analyzed, there are also gaps in the mechanisms to be followed in transporting the specimens collected from one level of health facility to the next in addition to lack of clear cut standards on which type of specimens can be collected and analyzed in a particular health facility level, and no clear cut protocols as to who in the health sector has the mandate of transporting collected evidence from the hospital to the police and vice versa.

\section{Retrieval and analysis of collected samples}

Any forensic evidence has to be taken by a government doctor yet the doctors lack experience on how to retrieve forensic evidence from the survivors of SV. Many cases get dismissed because of lack of corroborative evidence. The limited analysis at the district level often needs to be supplemented by the government chemist. Storing medical evidence is difficult as many hospitals and medical centres do not have adequate refrigeration facilities. Challenges therefore arise as to how the collected evidence can be documented, packaged, stored and transported to the government chemist for analysis.

The above gaps provided a basis within which this study was carried out in Kenya. This study aimed at identifying the requirements for increasing the utility of evidence collected from SV survivors at health facilities (using the PRC1 form) in the criminal justice system. It also aimed at strengthening links between prevention of SV, negative health outcomes, care and delivery of justice. 


\section{METHODS}

\section{Objectives}

The study objectives were as outlined below:

1] To describe the current practices and gaps in the collection, storage, analysis, documentation and transportation of evidence collected from survivors at the hospitals and police stations in the context of SV.

2] To design and test an evidence chain model applicable to the Kenyan system for obtaining and transporting samples from the primary health facilities to the government chemist.

3] Evaluate the model developed for functional custody of evidence chain suited for the Kenyan context.

\section{Design}

In order to achieve the study objectives, an exploratory design was used. Two districts were targeted, from which 2 district hospitals and 2 police stations were purposively sampled as the study sites. The selection criterion of the study sites was based on the existing collaboration between the health facilities and the district administration system in the selected regions. These sites were also selected as they had functioning laboratories and the health care workers were trained in physical examination of survivors of sexual violence and documentation procedures in evidence collection.

The process used in implementing this study involved the collection of data from the above mentioned facilities with an aim of establishing whether the chain of evidence was being maintained in the two districts, and if not, reasons behind this. In order to identify alternative solutions towards the already identified problem, an intervention was put in place in one of the districts aimed at informing the possible strategies that would be considered applicable in addressing the problems identified during the baseline.

\section{Study sample and data collection methods}

Purposive sampling was utilized in selecting respondents from the health facility, police stations and government chemist. Respondents were drawn from service delivery points (SDPs) within the hospital and police station where survivors of SV are usually attended from, namely Outpatient Department (OPD), Comprehensive Care Clinics (CCC), Wards, counseling rooms, laboratory and gender desks. The baseline sample was 29 while the endline sample was 24 health care workers and police officers drawn from 2 districts. (Refer to Table 1). 
Table 1: Study respondents at baseline and endline

\begin{tabular}{|c|c|c|}
\hline Characteristics & Baseline $(n=29)$ & Endline $(n=24)$ \\
\hline \multicolumn{3}{|l|}{ Sex } \\
\hline Male & 15 & 12 \\
\hline Female & 14 & 12 \\
\hline \multicolumn{3}{|l|}{ Designation } \\
\hline Clinical officer & 6 & 3 \\
\hline Laboratory officer & 6 & 4 \\
\hline Nurse & 4 & 7 \\
\hline Nurse in charge & 0 & 4 \\
\hline Medical doctor & 2 & 2 \\
\hline Police officer & 4 & 4 \\
\hline Legal officer & 4 & 0 \\
\hline Social worker & 3 & 0 \\
\hline
\end{tabular}

Both the baseline and end-line data collection exercises were administered in the same 2 hospitals and 2 police stations targeting respondents stationed in the above mentioned service delivery points. However at baseline, data was also collected from the laboratory analysts' working with the Government Chemist office in Nairobi, legal practitioners and social workers stationed in Nairobi to establish the current practices around maintenance of the evidence chain in the context of sexual violence.

Data were collected using an in-depth interview guide. Interviewers received two-days training on how to administer the interview guide and observe ethical procedures. Data were collected through face-to-face interviews. The same research team was involved in the entire research process from baseline to endline. Data from the hospital records were captured through photocopying of existing records from 2004 when the post rape care (PRC) services begun being offered in the selected health facilities to when the study was being conducted in 2007 with an aim of establishing the degree to which the existing records were being utilized by the service providers as part of their medical and legal notes.

\section{This data included:}

a] The PRC 1 forms - captured survivors name, date and time of presentation, age, sex, date and time of assault, physical examination taken, and samples collected for analysis.

b] The laboratory register - captured specifically the tests undertaken and the results for each test, signature of the lab technician who handled the samples and did the tests as well as the signature of the police officers who picked up the specimen.

\section{Ethical considerations}

The study protocols were reviewed and approved by the Kenyatta National Hospital and the Population Council Ethics Review Boards. Interviewers were trained on confidentiality and research procedures. Permission to interview the respondents was obtained from the in-charges of the various facilities targeted during this study. Informed consent to conduct and tape record the interviews was obtained from all respondents either orally or in written form. Participation of the respondents in the study was 
voluntary and no payment or incentives were offered to the study participants. Interviews were conducted in a private place and no identifying information was recorded on the transcripts. All research material including data collected were kept in lockable cabinets with access restricted only to the research team.

\section{Data management and analysis}

The following were the key study variables: collection of samples; storage and analysis of samples collected; transportation; prevention of loss \& contamination of samples; and documentation procedures used. At the end of the baseline and end-line data collection exercises, the raw data was subjected to familiarization, content analysis, coding and interpretation.

Transcriptions of the interviews were undertaken as soon as it was possible after the interview. A context summary sheet was attached to each data collected and reflected the basics of the interview with focus on: interview date, respondent's demographics; issues emerging, and quality of the data collection process. The context summary sheet was handed in by the research team alongside with all the data. Content analysis of these data based on the merging themes was then done using NVivo 8- qualitative data analysis software. Triangulation of information obtained from the different key informants at baseline and end-line was undertaken.

Quantitative data captured from hospital records was entered and analyzed by doing cross tabulations of selected variables using Epi Info 7.

To evaluate the practicality of the intervention put in place as mechanisms of providing strategies for improving on the maintenance of the evidence chain, the study team made a comparison of the data collected at end-line against the baseline data. The following outcomes were measured: level of utilization of existing medico-legal documentation with a focus on the PRC 1 form and rape registers within the health facilities; sample collection, storage, analysis and transportation of evidence; as well as utilisation of the rape kit .

\section{Limitations of the study}

1] The review of records during this study was based on patients' data that was captured for purposes that did not involve the research aspect. Hence the study team had no control over the extent to which all the survivor details were properly captured using the PRC 1 form and hospital registers.

2] It was also not possible to review police records as access was not granted to the study team. This therefore made it impossible to establish the "paper trail" of evidence collected from the health facility through to the police, and/or vice versa.

3] This particular study focused on the health and criminal justice systems in as far as maintanance of the evidence chain is concerned. The study did not however focus on the community, though community aspects and gaps were revealed from the data collected. 


\section{DESCRIPTION OF THE INTERVENTION}

The intervention was carried out during the period March to October 2008. The intervention activities were aimed at:

Informing discussions around what is the minimum evidence to be collected from survivors of SV and having joint trainings of stakeholders drawn from the hospitals and police stations on their distinct role in the maintenance of the evidence chain;

- Consensus building on the components of the rape kit, and Information, Education and Communication (IEC) materials to be developed;

- Strengthening the documentation used in the context of SV for survivors who present at the hospital and/or police station; and

Piloting a joint training module on evidence collection, preservation and analysis targeting service providers drawn from the police and health facility.

The partners involved in these activities included LVCT, Division of Reproductive Health (DRH), and the Government Chemist.

\section{Implementation of activities}

\section{Sensitization workshops}

The workshops were conducted over a period of one week with the HCWs, police officers and representatives of the community. The participants targeted for these workshops were those who were found to be attending to survivors of SV, despite them not having been trained on the same. Components of the existing national curricula on clinical management for survivors of sexual violence were adapted for these workshops that were facilitated by experts drawn from the medical, forensic medicine and legal sectors. The first two days of the training targeted the HCWs who were taken through medical management of SV survivors and collection of forensic evidence from survivors. Thereafter the police were sensitized on the legal provisions on SV in Kenya and also crime scene management. A community component was included with a focus on how the community members can assist survivors' access both medical and legal services as well as their rigths. The last day of the 5 days' workshop was set aside for a joint session with representatives from all three groups of stakeholders as a way of building consensus on how best to assist survivors of SV within the community and existing medico-legal institutions.

Although the focus on these workshops was on how to preserve evidence and maintain the evidence chain, participants were also informed on the type of services available for survivors of SV at the hospital and the police station.

\section{Development of protocols and tools for evidence collection, storage and transportation}

An algorithm highlighting the steps to be undertaken in collecting and documenting evidence collected from both adult and child survivors was developed and dispatched to every SDP at the hospital. This checklist was reviewed by both the police and HCWs in one of the trainings before being printed out. The checklist was also reviewed by members of the gender program within the DRH before it was disseminated to the sites. Copies were availed to all service delivery points involved in the delivery of PRC services within the health facility (Annex 2). 
In order to raise awareness in the community, the study team also developed a brochure on what to do and not do when SV occurs, while focusing on forensic evidence as well as timely medical management. These brochures were printed out in English and Dholuo, being the two languages predominantly spoken by the community in one of the sites. After the end line phase, these brochures were translated into Kiswahili, one of the two national languages in Kenya.

At baseline, it was established that the lack of refrigeration facilities in both study sites posed a challenge for the health care workers in maintaining the integrity of the evidence collected. It was also realized that the post rape care records were not kept under lock and key. The lack of proper filing of patient data could be assumed to increase chances of alteration and/or loss of hospital records, hence difficulties in adducing them in court as part of medico-legal evidence. During the intervention phase of the project, a refrigerator and a cabinet for storing samples received from survivors and the duly filled in PRC 1 forms respectively, were availed to the sites.

\section{Development of a rape kit}

Discussions were held between the researchers, the clinical officers and program staff within the LVCT post rape care programme, a programme officer from the Population Council, the government chemist and the DRH on what was the minimum evidence that could be collected from survivors at the district level. These discussions also focussed on whether there was already a rape kit in existence, and it was established that there was no rape kit in Kenya by that time. Discussions were also held with the district health management teams in the intervention site on whether to have a pre-packaged kit or a locally assembled one. Consensus was arrived on having a locally assembled rape kit whose components could be easily accessed in resource poor settings, especially with focus on the developing countries that lack proper commodity supply mechanisms for their health facilities. The need for a rape kit was informed by the current gaps within the public health facilities around collection of required medical evidence by HCWs due to either lack of required equipments, for example, speculums or the logistical challenges on handling stock-outs of the required equipment. The rape kit assembled included items shown in table 2 below. The rape kit was then used in one district hospital as part of the intervention. The level of utilization of the rape kit was not evaluated as part of the study due to time constraints and also the minimal numbers of survivors of SV reporting to the health facilities that made it impossible to evaluate utilization of the 200 rape kits that were assembled as part of this study.

Table 2: Rape kit content list

\begin{tabular}{|c|c|c|}
\hline Description Of Item & Quantity & Use \\
\hline Powder free gloves & 1 & To avoid contamination. \\
\hline Six stick swabs & 6 & For taking the HVS and/or anal swabs from the survivor. \\
\hline Masking tape & 1 & $\begin{array}{l}\text { Sealing the brown envelopes in which the specimens have been } \\
\text { stored. }\end{array}$ \\
\hline $\begin{array}{l}\text { Brown envelopes for } \\
\text { collecting samples }\end{array}$ & 20 & For proper storage of collected specimens. \\
\hline Tape Measure & 1 & Measure the physical injuries, if any, that are found on the survivor. \\
\hline Needles \& syringes & 3 & Collection of blood samples. \\
\hline Urine bottles & 3 & Collection of urine samples. \\
\hline Vercutainer tubes. & 1 & Collection of blood samples. \\
\hline Speculum & 1 & Collection of specimens from the vaginal cavity. \\
\hline Labels & 10 & $\begin{array}{l}\text { Labelling the brown envelopes with the details of the specimens stored } \\
\text { inside. }\end{array}$ \\
\hline
\end{tabular}




\section{Training on documentation}

Training of police officers and HCWs on issues around the evidence chain such as documentation and the referral of survivors was done. These trainings were informed by the baseline findings that indicated a large number of the HCWs were providing post rape care services before undertaking a course on post rape care management of survivors of sexual violence. The training also focused on the use of the PRC 1 form and the P3 form as medico-legal documents.

A 5-day training module was used that focused on having separate trainings for the health care workers and police and 1 joint training for the health care workers, police and community leaders (See Annex 1). These trainings were mainly focused on the role that each of these stakeholders play in the maintenance of the chain of evidence. These trainings were conducted in close collaboration with the Government chemist staff, with an aim of equipping service providers drawn from the health facility, police station and the community on the essentials of maintaining the evidence chain in the context of sexual violence. Four trainings were held during the intervention period with 303 participants drawn from the police, health facilities and community. However, it was established that some participants may have been trained more than once, since the selection of participants was done by the management of the study sites from the same service delivery points.

Through the training, it was also realised that some of the HCWs had either never seen the P3 form or didn't know how to fill in the PRC1 form together with the P3 form. The research team therefore obtained a copy of the P3 form that was used during the supervisory visits to facilitate cross learning among the HCWs and the police on the complementing role of the PRC1 form to the P3 form (Annex 3\&4).

As part of the study, PRC1 forms were printed out and HCWs alongside the heads of the health facility were taken through the filling in of the PRC1 forms. It was established through these forums that there is need to review the national guidelines on the medical management of rape/SV to clearly indicate the minimum type of evidence to be collected and by whom, as well as establishment of what type of evidence is required and analysable by the goverment chemist in order to sustain a prosecution in court. It was also realised that there are certain gaps in the current PRC 1 form that ought to be rectified, with specific focus on:

Who should sign for the evidence collected from survivors by the health care workers and handed over to the police?

When should the original copy of the PRC1 form be given to the survivor?

Should the PRC1 form be given after the initial visit to the health facility or at the end of the 3 months when they return to the facility for a repeat HIV test?

\section{Continuous monitoring}

As part of the study activities, regular supervision of the implementation of the intervention activities was carried out by the LVCT study team. A total of 3 supportive supervisory visits were done to:

Support the HCWs by addressing some of the challenges experienced in filling in the PRC 1 and P3 forms;

Collect survivors' data from the hospital records to assess the level of utilization of the PRC 1 form and lab registers;

Disseminate a brochure that had been developed to sensitize the community on what they need to do in the event of a sexual assault. 


\section{FIN D I NGS}

This section expounds on the findings obtained during the baseline and end line phases of this study. Data demonstrates improvements in terms of quality and completeness of evidence collected.

\section{Type of evidence collected}

According to the WHO guidelines for the medico-legal care for survivors of sexual violence, the evidence to be collected from survivors should include: clothing, genital, anal \& oral swabs, blood, urine, nail \& skin scrapings, hair, and sanitary pads/tampons.

During baseline phase of this study, it was established that the 3 types of samples were retrieved from survivors who presented at the 2 district hospitals, namely: high vaginal swab, blood and urine. Varied reasons were given as to why these samples were obtained from survivors. According to one respondent:

$$
\begin{aligned}
& \text { "HVS:--.' to check if there is any spermatozoa present; Urine for carrying out a PT } \\
& \text { Pregnancy Test. Blood is also taken for the purpose of checking on their haemoglobin } \\
& \text { levels. Some investigations are also done to the rapist so that we can also see what } \\
& \text { it is that they may have passed on to the client as they raped them." }
\end{aligned}
$$$$
\text { Laboratory In-Charge, District A1-Baseline }
$$

The respondents interviewed at baseline, indicated that HVS is usually obtained to detect the presence of spermatozoa. This in itself is inadequate as there are instances where the perpetrators would have used a condom or were azoospermic. The absence of spermatozoa does also not rule out the occurrence of the assault. During baseline, there was no mention among the police personnel interviewed on whether they collected samples from the scene of crime (environment where the crime took place). This raised questions on the degree to which evidence from the scene of crime can be utilized to corroborate the survivors' story.

The afore mentioned knowledge gaps also formed the basis of the trainings that were conducted during the second phase of the study where emphasis was on the types of evidence to be collected, from who and the type of analysis to be carried out.

During the endline phase, some of the police officers interviewed described measures that are undertaken with an aim of preserving the scene of crime even when the evidence is being collected: the police officers mentioned that the scene of crime is marked until a photograph of the place is taken; they described the importance of marking in case any component is moved/ shifted; and they also highlighted the use of special gadgets while collecting evidence from the scene of crime. 
"At the scene we preserve the scene, the things at the scene are marked until photograph of the place is taken so if there is need for anything to be moved it must be marked where the thing wasthe scene has been preserved and we must collect evidence from there using special gadgets, label them, then from there we come at the police station we record in the $O B$, then we mark them we prepare an exhibit memo we tell an officer take this to the government institution, like the government chemist in Nairobi."

Male Police Officer, District 02-Endline

There was also a marked difference in the responses obtained from HCWs during the end line phase, as many of them indicated that in addition to collecting HVS, blood and urine, they also obtain anal swabs, soiled or torn clothes worn during the attack, nail scrapings and oral swabs. (Table 3)

Table 3: Types of samples collected at baseline and endline

\begin{tabular}{|c|c|c|}
\hline Evidence collected by & Baseline & Endline \\
\hline Health care workers & $\begin{array}{l}\text { HVS, urine, clothes/pants, blood, } \\
\text { document injuries }\end{array}$ & $\begin{array}{l}\text { HVS, urine, blood, rectal \& oral swabs, hair, } \\
\text { clothes(torn/stained), pants, nail scrapings }\end{array}$ \\
\hline Police(from scene of crime) & $\begin{array}{l}\text { Clothes,panties,P3 form } \\
\text { (Rely on evidence collected by HCWs) }\end{array}$ & $\begin{array}{l}\text { Photos of scene of crime, money (especially } \\
\text { from child survivors) , clothes, panties, P3 form. }\end{array}$ \\
\hline
\end{tabular}

The above table highlights the types of samples collected from survivors as mentioned by respondents during the interview. These differences in the type of evidence collected from survivors at both sites during baseline and end line could be attributed to the trainings that were conducted during the intervention where health care workers and the police were capacity built on the types of evidence that should be collected from survivors when they present at the health facility.

However from the health facility records collected at both baseline and during the endline, it was not clearly established why the samples that had been mentioned by the respondents during the interviews were not documented in the PRC 1 form. Figure 1 below, focuses on the type of evidence collected from survivors as documented in the PRC 1 form during baseline and endline. 
Figure 1: Gaps in evidence collected as indicated on the PRC 1 form

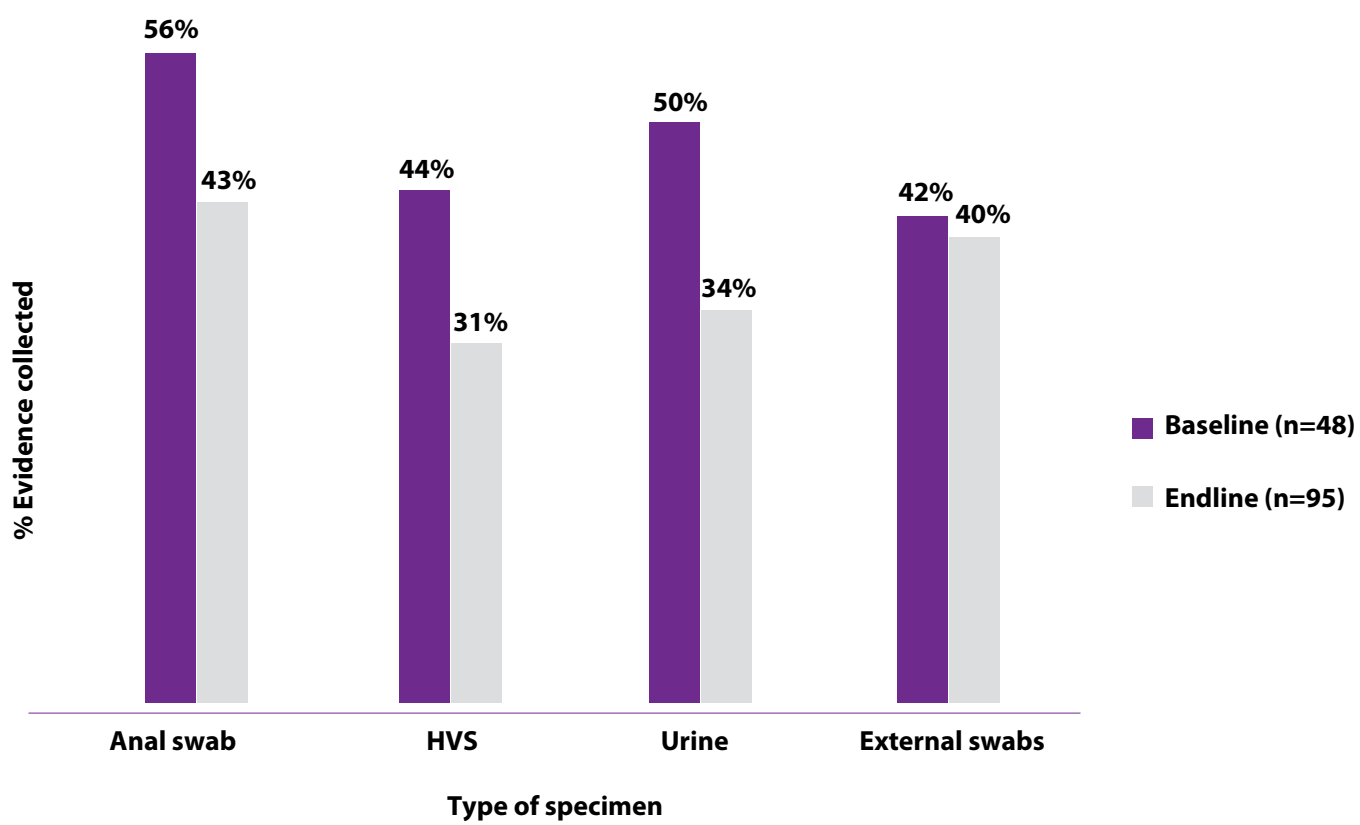

Note: External swabs were mostly collected from children due to the inability of the HCW s to retrieve a HVS.

The figure above clearly indicates that at baseline the PRC 1 forms were not filled in correctly, especially to highlight the type of samples collected from survivors who presented at the health facility. During the intervention training activities, focus was placed on training of HCWs on the importance of filling in the PRC1 form as a medico-legal document and the need to have it duly filled in by the attending clinician. At the endline phase, there was a reduction in the number of cases where survivor details were not indicated, and an increase in the number of cases where the type of evidence retrieved was properly documented in the PRC 1 forms(refer to figure 2 below). There is, however, need to do an evaluation study to establish the impact of the training based on the utilisation of the PRC1 forms.

Figure 2: Improvement in specimen collected as indicated on PRC1 forms

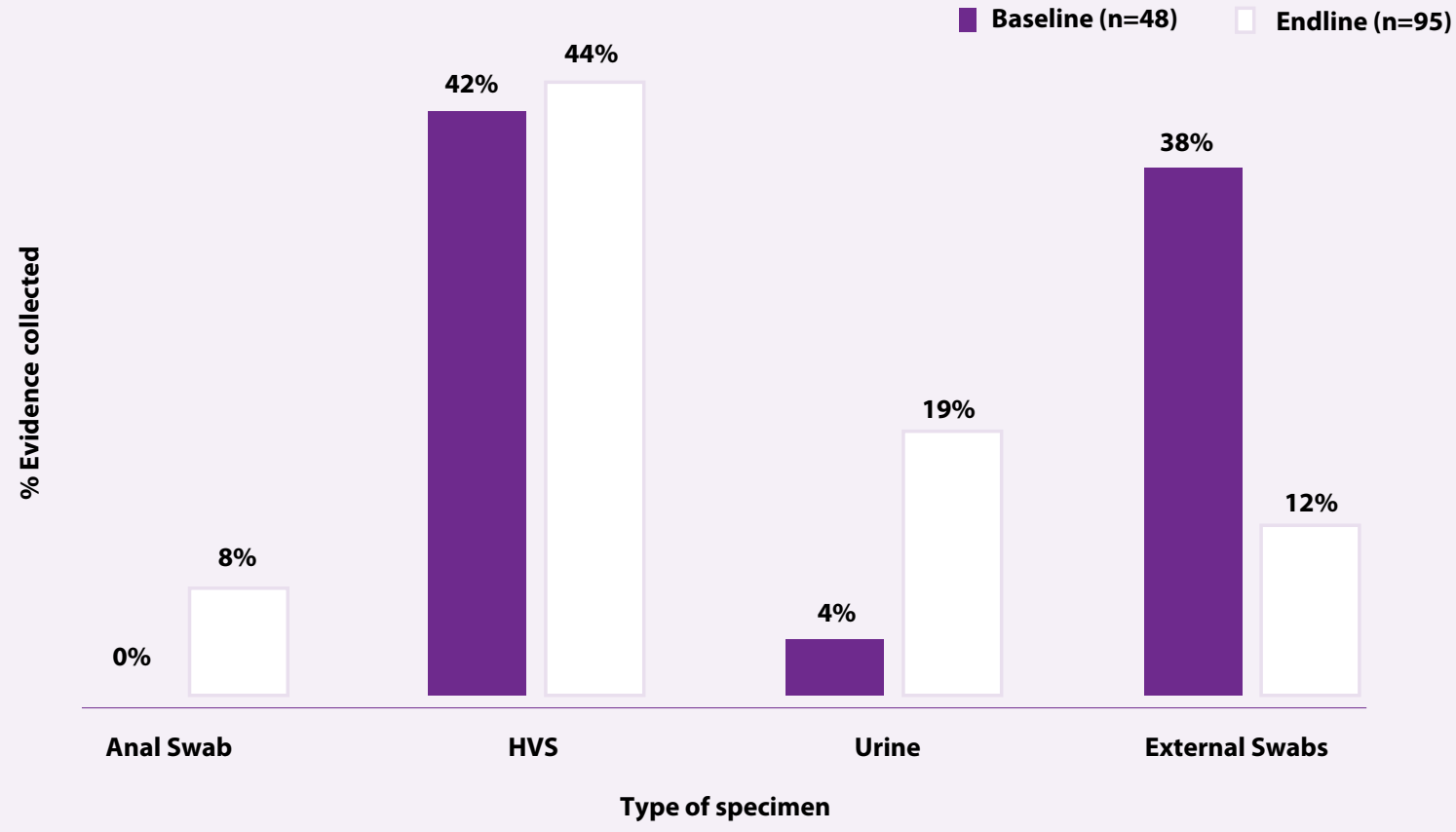


Figure 2 shows an improvement in the extent to which evidence was collected and documented in the PRC 1 forms. However, there still remains a challenge with the collection of external swabs from survivors, most of whom are children.

\section{Who collects the evidence}

The Kenya National Guidelines on the Management of Rape/Sexual Violence stipulate that the examining medical doctor is the one who is required to retrieve samples from the survivors' body. The medical doctors are also required to fill in the required medicolegal documentation, namely the PRC 1 and P3 forms, in addition to adducing the evidence in court. The police on the other hand are required to collect evidence from the crime scene and are the custodians of the evidence that is collected to corroborate the occurrence of the assault.

It was however established during baseline that all samples with the exception of blood are collected by the clinical officers, nurses and /or doctors and sent to the health facility laboratory for analysis. In some instances, the survivor was required to present themselves in the laboratory for blood sample collection. This practice was found to be dependent on who was on duty or the type of management in existence at various service delivery points, when the survivor presented at the health facility.

$$
\begin{aligned}
& \text { "Mostly, the patientsvictims are sent to the laboratory or if the clinical officer is } \\
& \text { available in the ward he takes the specimen." }
\end{aligned}
$$

Paediatric Nurse, District O1-Baseline

During baseline all the police respondents interviewed indicated that they never retrieve any evidence from the survivors' body as this was the work of the doctors. The police only collected clothes and panties from survivors who presented at the police station first, for onward transmission to the hospital or government chemist for further analysis. In instances where the survivor presented at the health facility before reporting to the police, then the HCWs interviewed indicated that they retrieved both the medical and scanty forensic evidence, whose results were then forwarded to the police together with the P3 form that would have been filled in by the doctor at the hospital. One police respondent also said that in cases where a child was given money by the perpetrator, the money was also considered as part of the evidence. During both baseline and end line, it was established the police in most instances only rely on the evidence collected by doctors/health care workers (Table 3).

"Or maybe like there was a case, the child was defiled, she was given money by the perpetrator. So the money is also evidence. The rest are being collected by the police."

Female Police Officer, District O1-Endline

The trainings done during the intervention period by one of the government chemist analysts was geared towards equipping HCWs on how to collect and preserve evidence collected using the existing resources and also on how to maintain proper documentation that would in turn be forwarded to the police as part of the corroborative evidence. From the end line data, it was established that 20 out of the 25 respondents interviewed did retrieve evidence from survivors who presented at the hospital 
after being sexually violated. This could therefore mean that with more trainings and also consistent supply of the required evidence collection equipments, HCWs would be better placed to collect relevant evidence from survivors who present post sexual assault.

\section{Tools used to collect samples}

According to the WHO guidelines for the medico-legal care for victims of sexual violence, the essential commodities required by a health facility in the provision of minimal services to survivors of SV include: examination couch, chairs, light, toilet, telephone, tourniquet, swabs, syringes, blood tubes, speculums, gloves, pregnancy kits, sterile water, sharps container, microscope slides, urine specimen containers, drop sheet, and paper bags. It is assumed that all these commodities are readily available in all health facilities.

At baseline, all the 17 health care respondents interviewed, mentioned that they used swabs, needle, syringe, speculums, gloves, two types of bottles- (one plain and the other one having anticoagulants), and improvised applicator sticks to retrieve evidence. However they did indicate that there were instances where the required reagents and equipments were not enough or could not be purchased by the health facility due to the cost implications. As to whether there was any difference in the type of tools used on adults and children, one respondent mentioned that certain samples like the HVS could not be retrieved from children as that would have meant the use of a speculum. In addition to the use of a speculum being traumatic, they did mention the unavailability of speculums within the health facilities and their lack of skills to obtain a HVS from children

"Also like now the way I have mentioned those rape kits and sometimes we need to use a speculum, most of the times I don't use that because actually we still need to improve on that one and I think it is because of that lack of training because we actually examine them just like any other patient"

Clinical Officer, District O1-Baseline

"Forensic we do, although we have some handicaps in that like the kind of lighting system we have is not as we wish it would be. Also some examination equipment we have are not up to date, we are using what is a vailable."

Clinical Officer, District O1-Baseline

"Children are a special group, they are very difficult to handle. Because number one they are traumatised. A child who has been sexually assaulted does not even want to see any male around. 
During baseline some respondents indicated that sometimes there are survivors who decline to undergo evidence retrieval or even examination. One respondent mentioned the lack of knowledge on how to use a speculum, while another respondent brought out an issue about their inability to draw certain samples which couldn't be analyzed at the district health facility level due to the kind of inadequate and ill equipped facilities available. This aspect was thus addressed through the provision of the rape kits and training of service providers during the project period.

In one of the health facilities, the respondent said that they experience challenges if the doctor who is mandated to retrieve samples from survivors is not around.

"-- but most of us when there is a case of rape, and a certain doctor is not there, you see, they cannot be handled properly."

Clinical Officer, MCH Clinic, District 02

These responses informed the local assembling of a rape kit composed of applicator sticks, vercutainer tubes, needles, pregnancy kits, syringes, powder free gloves, tape measure, urine bottles and a speculum. These items were found to be readily accessible from the hospital and could also minimize the level of wastage that is associated with pre-packaged rape kits. Health care workers were trained on how to use this kit by a government chemist analyst. 200 rape kits assembled were handed over to the health facilities to aid in the retrieval of evidence. However, due to project time constraints it was not possible to do an evaluation of the extent to which these kits were utilized properly during the end line phase.

\section{Documentation}

At baseline, respondents drawn from the police and health facilities stated that the following documents were used in cases of sexual violence: P3 form, PRC1 forms, a register, and the occurrence book. The respondents drawn from the health facilities mentioned the lack of a specific document that is used to refer a survivor from one Service Delivery Point (SDP) to the next. One respondent also said that there was no document in place to show the kind of samples that have been forwarded by a HCW in another SDP. Meaning that there was no "paper trail" of the evidence to show who handled it at what point within the health facility. The Police were however found to fill in details of the survivors who presented to them after an assault; however there were challenges in the terminology used to describe the type of complaint presented, whether it was a general assault or a sexual assault.

Most of the documents in use within the health facilities/police stations were found (at both baseline and endline) not to have slots for documenting referrals made at both and there was also no specific person responsible for PRC data

At baseline one respondent from one health facility said,

"instead of just using the PRC 1 form a lone, they also maintain files for each client indicating the state of the clothing, the state of the patient and whatever samples are taken----: 
Of the 7 health care workers who responded to the question on documentation procedures, 1 clinical officer who is based at the casualty department, which is the point of first presentation in most health facilities, did not know the kind of documentation that is maintained at the health facility for survivors of sexual violence. One rape trauma counsellor in one of the health facilities also did not know the kind of documents that are used.

"Those ones I don't know but am sure the clinician knows them. What I hear is they fill the PRC2 form, they also fill the P3 form and then there is the card, the client's card which they come with."

Trauma Counsellor, CCC, District A, Baseline

These 2 scenarios raised concerns on the information that the survivors are given when they present to the health facility for care, especially in Kenya, where the survivor is required to retain a copy of the PRC 1 form which is to be filled in by the examining doctor in triplicate. These aspects were however addressed in the trainings that were conducted during the intervention.

Training of health care workers and police on the proper filling in of the PRC 1 form, P3 form and the lab registers was also emphasised upon during the intervention. During endline, it was established that the health care providers in the intervention site had special registers for cases of SV, which were being used alongside the other documents that were being used at baseline

"We have a special prepared register for these rape cases." Laboratory Technician, District 02, Endline

Part of the study entailed an analysis of data collected from the PRC 1 forms to establish the maintenance of a paper trail for evidence that is collected. 
Figure 3: Whether police signed PRC 1 form

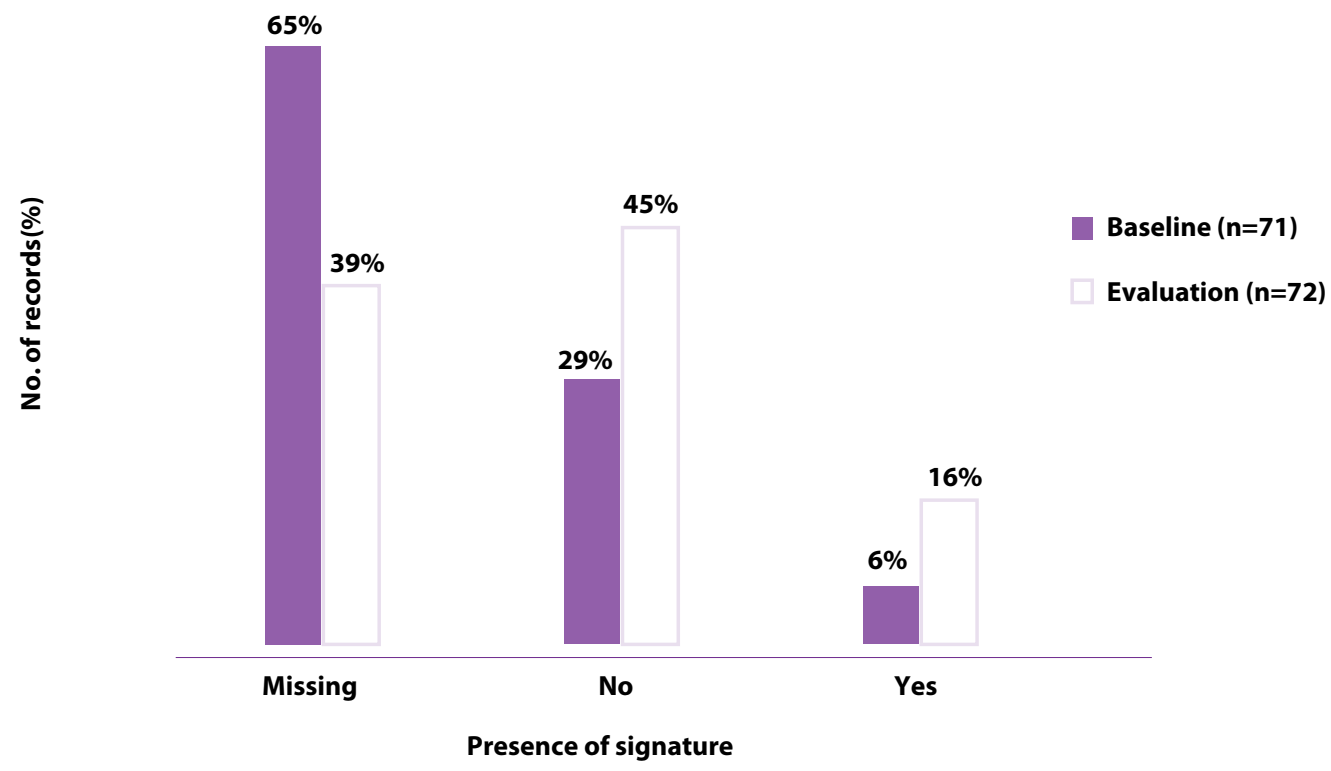

The figure above indicates that in $65 \%$ and $39 \%$ of the cases where evidence was handed over to the police, it was not possible to tell whether the police signed in the register or not. However, it was clear that in $29 \%$ and $45 \%$ of the cases attended to at during the baseline and at end line respectively, the police did not sign. This in itself indicated a lack of paper trail in the way evidence is handled or handed over from one institution to the next. Trainings were therefore carried out on the importance of maintaining a paper trail of collected evidence during the intervention. From the figure above, it can be observed that there was an improvement in the number of police officers who signed in the PRC 1 forms in 95 cases that presented at the facility during the intervention phase.

There were however challenges in effecting a paper trail system between the health facility and police station since both lie in different government ministries and policy directives are required in order to effect any changes in the existing documentation.

It is also worth noting that despite the training there were still many instances where the police did not sign in the health facility register for the evidence received. It is therefore necessary to extensively train health care workers and the police on the importance of maintaining a paper trail for evidence received from survivors.

\section{Utilisation of the PRC 1 forms}

An analysis of the health facility records was done to establish the extent to which PRC1 forms were filled for survivors of SV who presented at the health facility. The figure below clearly highlights this. 
Figure 4: Underutilisation of the PRC 1 form

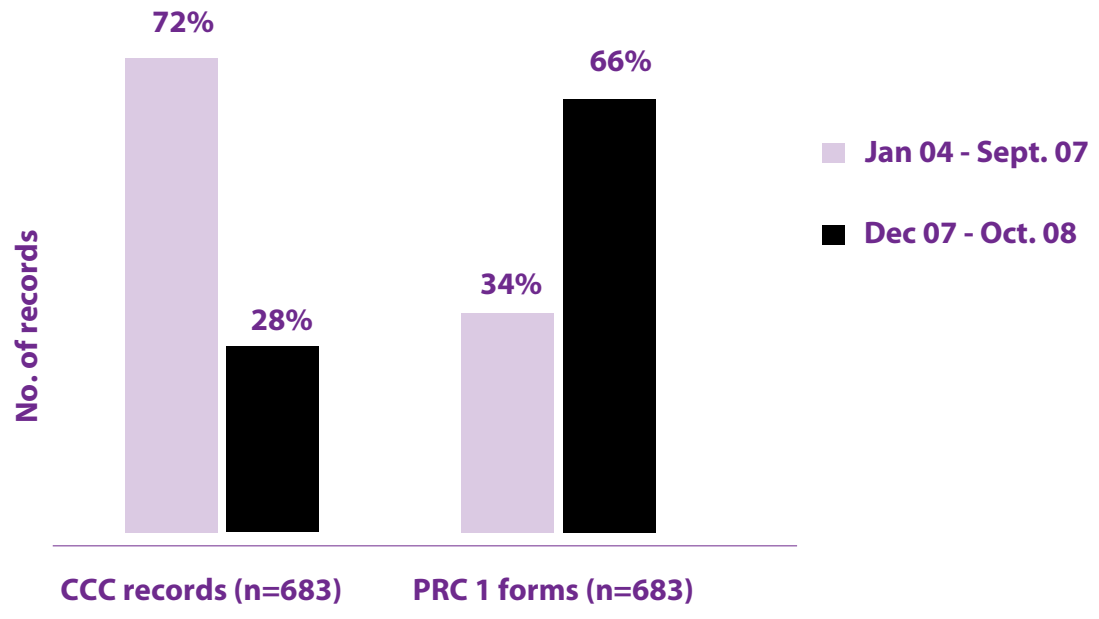

Type of record

Out of the 683 survivors attended to before and after the study period as indicated in the CCC register, it was established that only 20.9\% of them had a PRC 1 form filled in for them. It was not possible to establish how many of the survivors had a P3 form filled for them, as police records were not made accessible to the research team. Some of the reasons given why the PRC 1 was not filled in included: not having been trained in the provision of PRC services, lack of knowledge on the existence of this form, too much work involved in completing both the PRC 1\& P3 form, not all HCWs had seen this form since it was introduced as a Ministry of Health document in 2005/6, among others. However, it is worth noting that from the figure above there was an improvement in the utilisation of the PRC form during the project intervention and endline phase which could be attributed to the trainings conducted during the project in addition to the mechanisms put in place to supply the health facilities with PRC 1 forms.

\section{Storage and transportation of specimens}

The study sought to establish the procedures used in the storage and transportation of samples collected at the health facility. All the 4 laboratory personnel who were interviewed at baseline mentioned that they did not store any samples they received from other services. All the samples received in the laboratory are analyzed immediately. This was attributed to either the use of rapid testing methods on some of the samples e.g. the blood for HIV, or that the samples don't need to be stored in specific containers.

--- what I know it sample is not stored. Once it reaches there, they laboratory personnel work on it immediately."

Clinical Officer, CCC, District A, Baseline

However, one respondent mentioned that even in instances where refrigeration of samples is required, they cannot achieve this due to the non-functionality of the available fridge. In one of the sites, the respondents mentioned that they do not have a refrigerator specifically designed for specimens collected from survivors of SV. This in turn could be assumed to contribute to loss of samples or failure of service providers to maintain the integrity of the samples obtained. 
From the responses obtained at baseline, it was established that there is usually no transportation of samples outside the health facility since all specimens are analyzed within the hospital laboratory. No intervention was put in place to address this as the laboratory personnel indicated that they have the capability to handle all specimens at their level, but requested for support in provision of the essential equipments to be used in retrieving the samples and a refrigerator specifically designed for samples obtained from survivors of SV.

One respondent also stated that at times there is a delay in sample collection especially in cases where the survivors present at night when the laboratory is closed. All the analysis in district level health facilities is usually carried out in the laboratory, and since the only refrigerator for sample storage is located in the laboratory, then samples are not collected from survivors by other clinicians when the laboratory is closed. This in itself was found to contribute to the poor quality of evidence that is collected at the health facility subject to being handed over to the police in case further analysis will be required.

This raises a question as to whether all survivors who present at night are usually admitted overnight or they go back home the way they are but are still required to preserve all the evidence and present to the health facility the following day in the same state.

With regard to concerns raised at baseline on how to handle samples in instances when the district health facility laboratory does not have the required equipment and reagents to conduct analysis due to supply stock outs, the HCWs were sensitized by a government chemist analyst on preservation of evidence through air drying. The building of the HCWs capacity on the importance of air drying the samples that cannot be analysed within the district hospital laboratory before they are forwarded to the national government chemist laboratory for further analysis formed the focus of the intervention in so far as evidence preservation was concerned.

\section{Challenges at community level}

Despite the trainings undertaken during the intervention phase with an aim of addressing some of the challenges experience at baseline, it was noted at end line how delayed presentation of survivors to the health facility post sexual violence continues to interfere with the type of evidence collected from survivors.

"---there is a bit of a problem with the relatives come here, or the survivors come here having interfered with the evidence themselves so whatever you do, you know you have already lost, you have already interfered with the evidence." Medical Officer of Health, District 02

The table below gives a summary of some challenges in evidence collection mentioned by service providers at baseline and end line which are contributed to by the community 
Table 4: Challenges contributed to by the community

\begin{tabular}{|c|c|c|}
\hline & Baseline & Endline \\
\hline HCWs & $\begin{array}{l}\text { "--survivors come when they have } \\
\text { already bathed, they are already } \\
\text { changed the clothing and even washed: } \\
\text { the clothing sometimes there is no near: } \\
\text { by thing to wrap the clothing" }\end{array}$ & $\begin{array}{l}\text { "--there is a bit of a problem when the relatives } \\
\text { come here, or the survivors come here having } \\
\text { interfered with the evidence themselves...." } \\
\text { "ignorance sometimes on the part of the } \\
\text { victims" }\end{array}$ \\
\hline Police & $\begin{array}{l}\text { "Some of the cases are never reported } \\
\text { to the police. Others are being brought } \\
\text { here when after many months" }\end{array}$ & $\begin{array}{l}\text { "-family settlement of cases of SV especially } \\
\text { incest" }\end{array}$ \\
\hline
\end{tabular}

From the above quotes it is noted that the community play a key role in the maintenance of the chain of evidence, and therefore need to be sensitized on what needs to be done immediately one is sexually violated to avoid loss of evidence. The service providers also need to be sensitized more on what samples can still be retrieved from survivors even if they present at the health facility several hours after the assault. This component was covered in the trainings that were conducted in the intervention site by the government chemist personnel, but it is worth noting they still had concerns around how the community members handle themselves after an assault.

The knowledge gaps within the community on the role they play in maintaining the evidence chain through timely reporting to the health facility/police station necessitated the 2 trainings that were conducted among the community leaders and a joint training that was held between the community leaders, police and health care workers. A brochure stipulating the do's and don'ts after sexual violence was developed and disseminated for use within the community. There is however need for more sensitisations to be held at the community level since this was not a focus of this study.

\section{Evidence collection among children}

There were also challenges experienced with focus on children. One key point that was raised by many of the respondents at baseline was their lack of skills on how to handle child survivors. It was highlighted that children at times may not tell the same story throughout the examination while others may not be comfortable in being attended to by male physicians. HCWS also indicated their lack of experience in drawing samples from children and as such they end up collecting the wrong kind of sample.

"-you see they are not used to such kind of examinations, so they tend to...they are shy, so like some you end up getting the wrong specimen, instead of getting the high vaginal swab, you end up getting the outer swabs"

Clinical Officer, Casualty, District A, Baseline

Efforts were therefore made during the intervention to sensitize HCWs on how to handle child survivors. However, at the endline phase, there also emerged concerns among HCWs on the challenges they continued to face while collecting evidence from children. These challenges were attributed to various factors including lack of trust of health care workers by the children, and the prohibitions around using speculums on them. These challenges could also be associated with the fact that the focus of the 
training carried out during the project period was on sensitising service providers on the definitions of the various types of sexual violence; the minimum evidence to be retrieved using the rape kit; plus the documentation to be maintained for all survivors without necessarily focusing on the children. The training done during the intervention did not go into depths on how specimen should be obtained from child survivors of sexual violence as this was not part of the scope of this project.

---for kids it becomes complicated because you don't have any speculum for kids, even you can't insert a speculum on a kid surely"

Clinical Officer, District 02, Endline

"--getting challenges in getting history, consent, HVS, and physical examination when it comes to children"

Medical Doctor, District 02, Endline

However, some of the responses received indicated that there were provisions within the health facility for children to be admitted at the health facility so as to facilitate sample collection once they calm down. 


\section{CONCLUSIONS AND RECOMMENDATIONS}

This section highlights the key recommendations of the study based on the findings and conclusions drawn.

\section{Targeted training of HCWs and police officers is effective in improving evidence collection and documentation}

Evidence suggests that proper and continuous training of service providers could have a positive outcome on the type of services offered to patients. This was also found to be true in the context of this study. Programmatic experience also indicates that existing and new training programs provided on an ongoing, and repeated basis go a long way in enhancing the capacity of staff on the management of survivors of sexual violence. This was also established during the study, in that there was an improvement in the type of evidence collected and documentation maintained which could be linked to the multi-sectoral trainings that were held targeting stakeholders from the medical and criminal justice system.

\section{Ambiguity on who completes form undermines correct and complete documentation}

The key issue when it comes to comprehensiveness of evidence collection has to do with documentation. Currently the PRC1 form though in existence specifically for purposes of documenting cases of SV, its usage is yet to pick up since most service providers place more weight on the P3 form and not on the PRC1 form that was specifically designed for this purpose. There is also some ambiguity as to exactly who should collect evidence from a survivor and fill out the P3/PRC1 form and later produce the same as evidence in court. The common practice has been that only a qualified medical doctor has this responsibility and this has led to reluctance amongst other cadres of HCWs to collect such medico-legal evidence and fill in the required documentation.

\section{Lack of clarity on the purpose and use of medico-legal evidence inhibits evidence collection and documentation}

The medical forensic examination is conducted to collect available medico-legal evidence for potential use in court. However the study established that there are diverse views among service providers as to why certain types of evidence are to be collected; by when should the survivor present to the health facility for proper evidence to be collected, and the uses of the medico-legal evidence in as far as the medical and legal management of survivors is concerned.

It is envisioned that clear stipulations on the reasons why medico-legal evidence is to be collected will contribute towards improvement in the collection, storage, analysis and utilisation of evidence retrieved from survivors of SV.

\section{Better Strategies needed to improve community involvement}

It has been established that the community is key in the maintanance of the evidence chain as this is the scene of crime and in most instances the location of both the survivor and perpetrator. The community has also been found to have its own informal justice systems that respond to sexual violence and as such undermining human rights of the survivor while at the same time increasing vulnerabilities to continuous violations. Comprehensive utilisation of existing medico-legal services requires mobilisation and referral between all services providers from the formal and informal sectors within the community. 


\section{Providers need more training on addressing the special needs of children}

Statistics indicate that majority of survivors of sexual violence are children, yet most of the interventions put in place are not well targeted towards this group. From this study it was realised that many of the services providers in public health facilities lack the skill required to provide adequate and/or appropriate medico-legal care to child survivors of SV. This knowledge gap could be well addressed through training programs that are aimed at equipping the service providers with the required skill.

\section{A locally-assembled rape kit is promising but needs to be tested}

It is still uncertain on whether the availability of a rape kit would help enhance the collection of medico-legal evidence in resource poor settings. Existing debates indicate that there is still no consensus on whether a pre-packed rape kit is better than a locally assembled rape kit. However, during the piloting of a locally assembled rape kit during this study, it was established that there was an improvement in the types of evidence collected and that that there is need for addressing this subject with focus on resource poor health settings.

\section{KEY RECOMMENDATIONS}

The section below stipulates aspects that need to be addressed in order to address the current challenges on the maintenance of the chain of evidence

\section{Policy Recommendations}

The study recommends that proper guidelines be enacted to clearly stipulate that any medical practitioner involved in the delivery of PRC services should carry out the required forensic examination; fill in the PRC 1 and P3 form; in addition to being regarded as an expert witness by the CJS.

In order to improve the delivery of medico-legal services to survivors of SV and also address challenges around high staff turn over among staff who have been trained on PRC services, the Ministry of Public Health \& Sanitation and the Ministry of Justice and Constitutional Affairs should develop pre-service curricula that would facilitate training of all those who graduate through the different training programmes that fall under the mandate of these ministries are best equipped on how to deliver medico-legal services to survivors of SV.

For challenges experienced by HCWs on whether or not to fill in the PRC 1 form to be minimised if not eradicated, there is need for the Ministry of Public Health \& Sanitation in collaboration with the Office of the Attorney General to hasten the gazettement of the PRC1 form. Required revisions should also be made in the current PRC1 form to address the existing errors.

This study also adopts the same position as that of the desk review done by the Sexual Violence Research Initiative ${ }^{\mathrm{xx}}$ that there is need to examine the meaning of medical forensic examinations for survivors of SV in addition to reviewing the alternative legal measures that could enhance justice for them.

There is need for the establishment of what is the minimum medical and forensic evidence required to facilitate a positive legal outcome within the Kenyan context. This thus brings to fore the necessity of integrating the medical and legal protocols used in the medico-legal management of survivors of sexual violence. This integration might in the long run bring an end to the existing 
health, criminal justice and communal systems frameworks that not only impede access to services but also place blame on the survivors of SV.

There is need to clearly define where survivors of SV should first report to, is it first to the police, then the hospital vice versa. The necessary logistical arrangements also need to be put in place to ensure efficient internal and external referral of survivors for PRC services within the relevant institutions

\section{Programmatic recommendations}

There is need for HCWs, police and key community leaders be sensitised on what evidence can be collected within and even after the required 72 hours within which the survivor could benefit from existing prophylactic therapies. The management of the various institutions involved in the delivery of medical and legal services should also have continuous on-job training programmes that revolve around SV for all its personnel. The training program utilised during this study could also inform the training modules to be used by various stakeholders in capacity building their staff or strategic partners on the provision of medico-legal services.

Joint sensitization exercises should be carried out for the medico-legal service providers at the grass root level to enhance proper referrals. This study demonstrates that this nature of inter-sectoral trainings will be instrumental in facilitating proper utilisation of existing medico-legal documentation, knowledge transfer, and appropriate handling of evidence collected and stored by both the HCWs and police.

In order to promote effectiveness in the medico-legal management of survivors of SV through collection and preservation of evidence, provisions should be made to continuously equip the health facilities with essential components of a rape kit. This study suggests that this would aid in the collection of the required minimum evidence from all survivors of SV based on the type of SV reported, the age of the survivor, among others. All the health facilities should also be equipped with the necessary storage facilities that could contribute to the maintenance of the integrity of the evidence collected from survivors of SV.

Proper documentation is key in maintaining the integrity of the custody of evidence chain. Hence their is need for systems to be put in place that would enhance proper utilisation of existing medico-legal documents, namely the PRC1 form,P3 form and the registers/occurrence book by all those involved in the delivery of medico-legal services from the grassroots to the national level.

It has been demonstrated through various programmes that the majority of survivors of sexual violence are children and that the community attitudes, and practices contribute to the extent to which survivors present for medico-legal services in the health facilities and/or police station. There is thus a need for different stakeholders to develop mechanisms through which the community at large will be sensitised on the existing services and what is to be done in instances where the assault involves a minor. Health care workers on the other hand also ought to be sensitised on how to manage child survivors as through this study it was established that majority of them didn't have the required skill in handling child survivors. 


\section{Research recommendations}

This study suggests a need for further research on the areas mentioned below:

Evaluation of current programmes/interventions involved in the delivery of PRC to establish the effectiveness of the existing medico-legal services; training modules developed; and the practicality of the national policies that govern the medical management of survivors of SV.

- Identification of mechanisms through which the traditional justice systems can be integrated in the formal response to cases of SV with an aim of maintaining the evidence chain as well as provide timely medical management to survivors.

- An evaluation on the utilization of the rape kit in the two sites that were part of this study to help answer questions on whether a locally assembled kit is better than a pre-packed one, with focus on poor resource settings. 


\section{A N N EXES}




\begin{tabular}{|c|c|c|c|c|}
\hline Date & Time & Activity & Aim/Output & Method \\
\hline \multicolumn{5}{|c|}{ TARGET GROUP I: THE HEALTH CARE WORKERS (HCWs) } \\
\hline Monday & $8.00-8.30$ & Registration & $\begin{array}{l}\text { Health care workers from intervention } \\
\text { site to attend. }\end{array}$ & $\begin{array}{l}\text { Filling out of the } \\
\text { LVCT registration } \\
\text { forms. }\end{array}$ \\
\hline Monday & $8.30-10.30$ & $\begin{array}{l}\text { Training on: } \\
\text { Provision of prophylactic treatment to survivors } \\
\text { of sexual violence. } \\
\text { How to attend to child survivors who present at } \\
\text { the health facility. }\end{array}$ & $\begin{array}{l}\text { All HCWs to be fully conversant with } \\
\text { procedure on how to administer } \\
\text { prophylactic treatment to survivors. } \\
\text { All HCWs to be able to adequately } \\
\text { attend to child survivors. }\end{array}$ & $\begin{array}{l}\text { Interactive talk } \\
\text { utilizing power } \\
\text { point presentation } \\
\& \text { flip charts as } \\
\text { visual aids. }\end{array}$ \\
\hline Monday & $11.00-1.00$ & $\begin{array}{l}\text { Training on the collection \& examination of } \\
\text { specimens taken from survivors. }\end{array}$ & $\begin{array}{l}\text { HCWs involved in collection \& } \\
\text { examination of specimen (lab } \\
\text { personnel) are conversant with the } \\
\text { correct procedures. }\end{array}$ & $\begin{array}{l}\text { Interactive talk } \\
\text { utilizing power } \\
\text { point presentation } \\
\& \text { flip charts as } \\
\text { visual aids. }\end{array}$ \\
\hline Monday & $2.00-4.00$ & $\begin{array}{l}\text { View DVD on South African procedures utilized } \\
\text { in the collection, examination, preservation, } \\
\text { storage, \& transportation of evidence collected } \\
\text { from survivors of sexual violence. }\end{array}$ & $\begin{array}{l}\text { HCWs to be familiar with developed } \\
\text { practice and procedure as utilized } \\
\text { in other jurisdictions with stronger } \\
\text { medico-legal services. }\end{array}$ & DVD \\
\hline Tuesday & $8.00-10.30$ & $\begin{array}{l}\text { Training on the preservation of evidence/ } \\
\text { specimens collected \& examined from survivors. }\end{array}$ & $\begin{array}{l}\text { HCWs to be conversant with proper } \\
\text { preservation/storage procedures. }\end{array}$ & $\begin{array}{l}\text { Interactive talk } \\
\text { utilizing power } \\
\text { point presentation } \\
\& \text { flip charts as } \\
\text { visual aids. }\end{array}$ \\
\hline Tuesday & $11.00-1.00$ & $\begin{array}{l}\text { Training on the law on evidence as adduced in } \\
\text { cases of sexual violence in the Kenyan Criminal } \\
\text { Justice System. This covers: } \\
\text { Law governing witnesses as per the Evidence } \\
\text { Act (cap.80), the Criminal Procedure Code } \\
\text { (cap.75), the Sexual Offences Act (Act No.3 of } \\
\text { 2003), the Penal Code (cap.63) } \\
\text { What to expect when giving evidence. }\end{array}$ & $\begin{array}{l}\text { HCWs to be conversant with the } \\
\text { law on evidence in regard to cases } \\
\text { of sexual violence to enable them } \\
\text { to serve as better witnesses in } \\
\text { prosecution of sexual offenders. }\end{array}$ & $\begin{array}{l}\text { Interactive talk } \\
\text { utilizing power } \\
\text { point presentation } \\
\& \text { flip charts as } \\
\text { visual aids. }\end{array}$ \\
\hline Tuesday & $2.00-4.00$ & $\begin{array}{l}\text { Training on the law on evidence as adduced in } \\
\text { cases of sexual violence in the Kenyan Criminal } \\
\text { Justice System. This covers: } \\
\text { The minimum evidence required to sustain } \\
\text { successful prosecution of sexual violence cases. } \\
\text { Examination of case law to establish how cases } \\
\text { can be thrown out based on technicalities } \\
\text { occasioned by lack of observing proper } \\
\text { procedure. }\end{array}$ & $\begin{array}{l}\text { HCWs to be conversant with what the } \\
\text { courts consider to be the minimum } \\
\text { evidence sufficient to sustain a } \\
\text { conviction in cases of sexual violence. } \\
\text { HCWs to know what not to do in } \\
\text { regard to handling the evidence so as } \\
\text { to avoid the case being dismissed on } \\
\text { a technicality such as mishandling of } \\
\text { evidence. }\end{array}$ & $\begin{array}{l}\text { Interactive talk } \\
\text { utilizing power } \\
\text { point presentation } \\
\& \text { flip charts as } \\
\text { visual aids. }\end{array}$ \\
\hline
\end{tabular}

\begin{tabular}{|c|c|c|c|c|}
\hline Date & Time & Activity & Aim/Output & Method \\
\hline \multicolumn{5}{|c|}{ TARGET GROUP II: POLICE OFFICERS } \\
\hline Wednesday & $8.00-10.30$ & $\begin{array}{l}\text { Preservation of evidence collected from the } \\
\text { hospitals. }\end{array}$ & $\begin{array}{l}\text { Police officers know their role in } \\
\text { maintaining the integrity of the } \\
\text { evidence chain \& procedures of } \\
\text { preservation of evidence collected } \\
\text { from the survivors at the hospital to be } \\
\text { used in court. }\end{array}$ & $\begin{array}{l}\text { Interactive } \\
\text { talk utilizing } \\
\text { power point } \\
\text { presentation } \\
\& \text { flip charts } \\
\text { as visual aids. }\end{array}$ \\
\hline Wednesday & $11.00-1.00$ & $\begin{array}{l}\text { Training on the law on evidence as adduced in } \\
\text { cases of sexual violence in the Kenyan Criminal } \\
\text { Justice System. This covers: } \\
\text { The minimum evidence required to sustain } \\
\text { successful prosecution of sexual violence cases. } \\
\text { Examination of case law to establish how cases can } \\
\text { be thrown out based on technicalities occasioned } \\
\text { by lack of observing proper procedure. }\end{array}$ & $\begin{array}{l}\text { Police officers to be conversant with } \\
\text { what the courts consider to be the } \\
\text { minimum evidence sufficient to sustain } \\
\text { a conviction in cases of sexual violence. } \\
\text { Police officers to know what not to do } \\
\text { in regard to handling the evidence so } \\
\text { as to avoid the case being dismissed } \\
\text { on a technicality. }\end{array}$ & $\begin{array}{l}\text { Interactive } \\
\text { talk utilizing } \\
\text { power point } \\
\text { presentation } \\
\text { \& flip charts } \\
\text { as visual aids. }\end{array}$ \\
\hline
\end{tabular}




\begin{tabular}{|c|c|c|c|c|c|}
\hline Date & Time & \multicolumn{2}{|l|}{ Activity } & Aim/Output & Method \\
\hline \multicolumn{6}{|c|}{ TARGET GROUP III: COMMUNITY LEADERS } \\
\hline Thursday & $8.00-10.30$ & \multicolumn{2}{|l|}{$\begin{array}{l}\text { Training on the role of the community in addressing } \\
\text { cases of sexual violence. This covers, among others: } \\
\text { How they can help the survivor present at the hospital } \\
\text { in good time (before } 72 \text { hours lapse). } \\
\text { Reporting the occurrence of sexual assault to the police. } \\
\text { Preservation of evidence collected from the scene of } \\
\text { assault so that tests can be conducted on the items } \\
\text { at the laboratory to gather evidence to be used in } \\
\text { prosecution of sexual offenders. }\end{array}$} & $\begin{array}{l}\text { The community to know the } \\
\text { pivotal role they play in the } \\
\text { maintenance of the integrity } \\
\text { of the chain of evidence in } \\
\text { cases of sexual violence and } \\
\text { in helping the survivor access } \\
\text { health services post assault. }\end{array}$ & $\begin{array}{l}\text { Interactive } \\
\text { talk utilizing } \\
\text { power point } \\
\text { presentation } \\
\text { \& flip charts as } \\
\text { visual aids. }\end{array}$ \\
\hline Thursday & $11.00-1.00$ & \multicolumn{2}{|c|}{$\begin{array}{l}\text { Training on the need for reporting and the formal \& } \\
\text { informal justice systems. This covers: } \\
\text {. The need to report occurrences of sexual violence to } \\
\text { the police. } \\
\text { the pathway followed by the survivor upon reporting to } \\
\text { the police, through the criminal justice system. } \\
\text { Alternative/traditional forms of justice and their place in } \\
\text { seeking restorative justice for the survivor. }\end{array}$} & $\begin{array}{l}\text { The community to know } \\
\text { the solemn importance of } \\
\text { reporting incidences of sexual } \\
\text { violence to the police and } \\
\text { the channels followed by the } \\
\text { survivor through the criminal } \\
\text { justice system. }\end{array}$ & $\begin{array}{l}\text { Interactive } \\
\text { talk utilizing } \\
\text { power point } \\
\text { presentation } \\
\text { \& flip charts as } \\
\text { visual aids. }\end{array}$ \\
\hline Date & Time & Activity & & Aim/Output & Method \\
\hline \multicolumn{6}{|c|}{ TARGET GROUP IV: INTEGRATED SESSIONS (HCWs, POLICE, COMMUNITY LEADERS) } \\
\hline \multirow[t]{2}{*}{ Friday } & $8.00-10.30$ & $\begin{array}{l}\text { Talk on the referral mechanisms/the pathway } \\
\text { through which the survivor passes from the } \\
\text { moment s/he presents at the hospital. The talk is } \\
\text { addressed to the HCWs \& community leaders. }\end{array}$ & & $\begin{array}{l}\text { HCW's \& community leaders } \\
\text { ecognize existing gaps in the } \\
\text { ent referral mechanism and } \\
w \text { the proper referral paths to be } \\
\text { wed by the survivor. }\end{array}$ & $\begin{array}{l}\text { Group } \\
\text { discussion. }\end{array}$ \\
\hline & $11.00-1.00$ & $\begin{array}{l}\text { Referral mechanisms between health care workers } \\
\text { and the police. }\end{array}$ & & $\begin{array}{l}\text { Vs \& the police to know exactly } \\
\text { referral pathways through } \\
\text { ch the survivor is to pass when } \\
\text { first present at the hospital or } \\
\text { ce station. So that the survivor } \\
\text { 's from the police station to the } \\
\text { bital and vice versa. }\end{array}$ & $\begin{array}{l}\text { Group } \\
\text { discussion. }\end{array}$ \\
\hline Friday & $2.00-4.00$ & $\begin{array}{l}\text { Maintaining the integrity of the chain of evidence } \\
\text { in cases of sexual violence: How each target } \\
\text { group can play its role more effectively to ensure } \\
\text { the integrity of the evidence from the point of } \\
\text { collection up to its ending up as an exhibit in the } \\
\text { prosecution of the sexual offender. }\end{array}$ & & $\begin{array}{l}\text { group to know its role in } \\
\text { ttaining the integrity of the } \\
\text { ody of chain of evidence. }\end{array}$ & $\begin{array}{l}\text { Group } \\
\text { discussion. }\end{array}$ \\
\hline
\end{tabular}




\section{GUIDELINES FOR EVIDENCE COLLECTION IN THE CONTEXT OF SEXUAL VIOLENCE}

NOTE: The Process can be interrupted to cater for the comfort of the survivor of sexual violence.

When handling children, their guardian/parent can be present during the examination depending on the survivor's age and level of awareness.

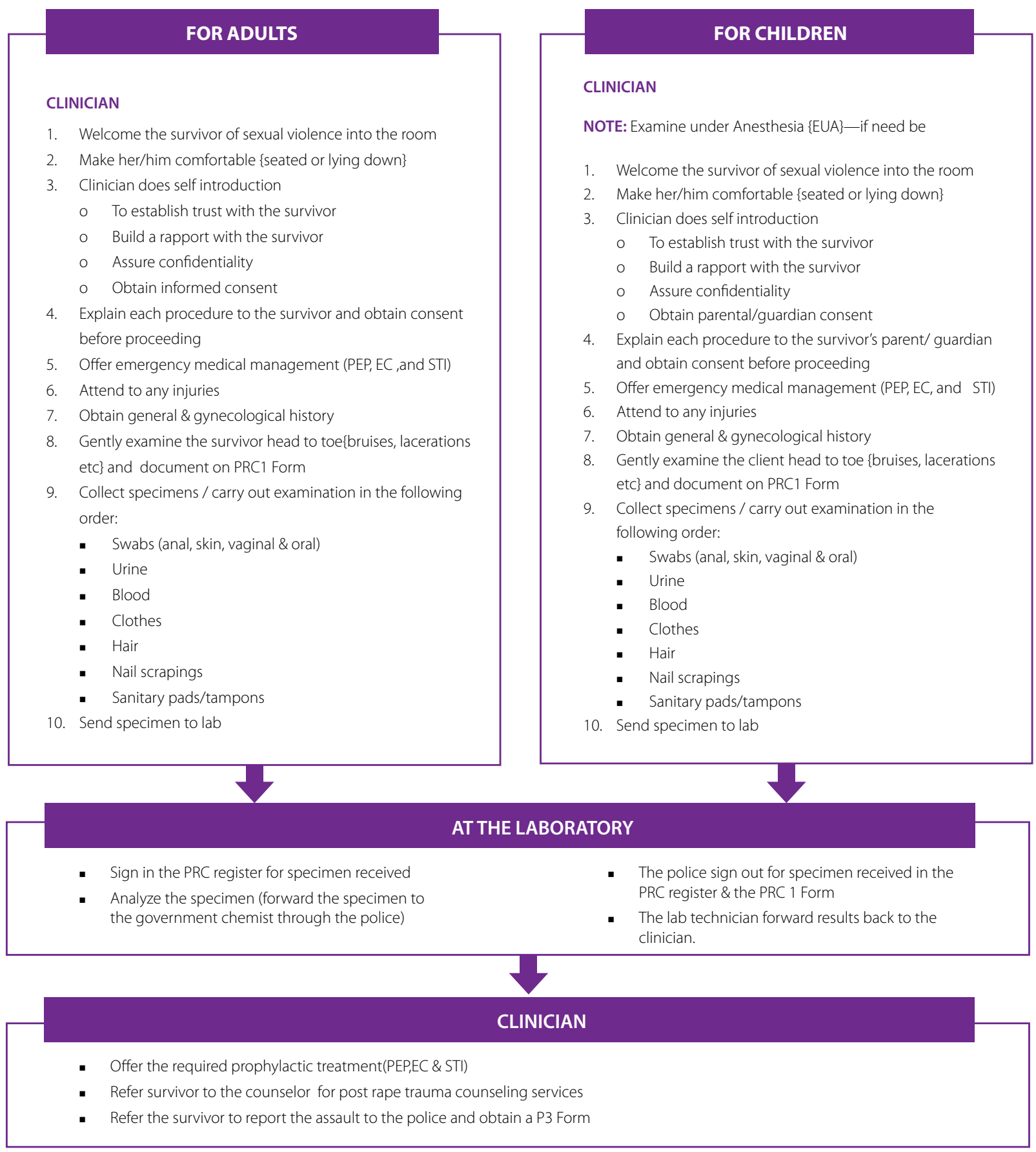

Remember to give the survivor the original copy of the PRC 1 Form after it has been duly filled. The yellow copy should be given to the police to support the P3 Form and the green copy should be retained at the hospital for documentation. 
Annex 3: P3 form

THE KENYA POLICE | MEDICAL EXAMINATION REPORT

PART 1-(To be completed by the Police Officer Requesting Examination)

From Ref...... Date

To the Hospital/Dispensary

I have to request the favour of your examination of:-

Name Age (If known)

Address Date and Time of the alleged

offence.

Sent to you/Hospital on the.

20.....under escort of

süstäinë by himin/hër. and of your furnishing me with a report of the nature and extent of bodily injury

Date and time report to police.

Brief details of the alleged offence.

Name of Officer Commanding Station Signature of the Officer Commanding Station

PART 11-MEDICAL DETAILS - (To be completed by Medical Officer or Practitioner carrying out examination)

(Please type four copies from the original manuscript)

\section{SECTION "A"-THIS SECTION MUST BE COMPLETED IN ALL EXAMINATIONS}

Medical Officer's Ref. NO

1. State of clothing including presence of tears, stains (wet or dry) blood, etc.

2. General medical history (including details relevant to offence)

3. General physical examination (including general appearance, use of drugs or Alcohol and demeanour) 


\section{SECTION "B"- TO BE COMPLETED IN ALL CASES OF ASSAULT, INCLUDING \\ SEXUAL ASSAULTS, AFTER THE}

\section{COMPLETION OF SECTION "A"}

1. Details of site, situation, shape and depth of injures sustained:-

a) Head and neck

b)ThoraxandAbdomen

c) Upper limbs

d) Lower limbs

2. Approximate age of injuries (hours, days, weeks)

3. Probable type of weapon(s) causing injury.

4. Treatment, if any, received prior to examination

5. What were the immediate clinical results of the injury sustained and the assessed degree, i.e. 'harm", or' grievous harm".*

\section{DEFINITIONS:-}

"Harm" Means any bodily hurt, disease or disorder whether permanent or temporary.

"Maim' means the destruction or permanent disabling of any external or organ, member or sense

"Grievous Harm" Means any harm which amounts to maim, or endangers life, or seriously or permanently injures health, or which is likely so to injure health, or which extends to permanent disfigurement, or to any permanent, or serious injury to external or organ. 
Date

\section{SECTION “C”-TO BE COMPLETED IN ALLEGED SEXUAL OFFENCES}

\section{AFTER THE COMPLETION OF SECTIONS “A” AND “B”}

1. Nature of offence. Estimated age of person examined.

\section{FEMALE COMPLAINANT}

a)Describein detailthephysicalstateofandanyinjuriestogenitaliawith special referencetolabiamajora, labiaminora, vagina, cervixand conclusion.

b) Note presence of discharge, blood or venereal infection, from genitalia or on body externally. .....

\section{MALE COMPLAINANT}

b) Describe in detail the physical state of and any injuries to genitalia

c) Describe in detail injuries to anus

d) Note presence of discharge around anus, or/ on thighs, etc.; whether recent or of long standing 


\section{SECTION "D"}

4. MALE ACCUSED OF ANY SEXUAL OFFENCE

a) Describe in detail the physical state of and any injuries to penis

b) Describe in detail any injuries around anus and whether recent or of long standing...

5. Details of specimens or smears collected in examinations 2, 3 or 4 of section " $C$ " including pubic hairs and vaginal hairs

6. Any additional remarks by the doctor

Name \& Signature of Medical Officer/Practitioner

Date 
Ministry of Health National rape Management guidelines: Examination documentation form for survivors of rape/sexual assault (to be used as clinical notes to guide filling in of the P3 form)

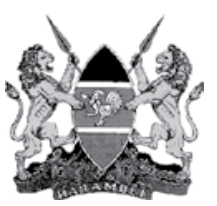

\begin{tabular}{|c|c|c|c|c|c|c|c|c|}
\hline \begin{tabular}{|l|l|}
$\mathrm{D}$ & $\mathrm{MM}$ \\
$\mathrm{A}$ & $\mathrm{M}$
\end{tabular} & DD & Year & Province Code & District Code & & & IP No. & \\
\hline \multicolumn{3}{|c|}{ Last Name } & First Name & $\begin{array}{c}\text { DATE } \\
\text { OF } \\
\text { BIRTH }\end{array}$ & $\mathrm{MM}$ & & Year & $\begin{array}{l}\square \text { Male } \\
\square \text { Female }\end{array}$ \\
\hline
\end{tabular}

Contacts

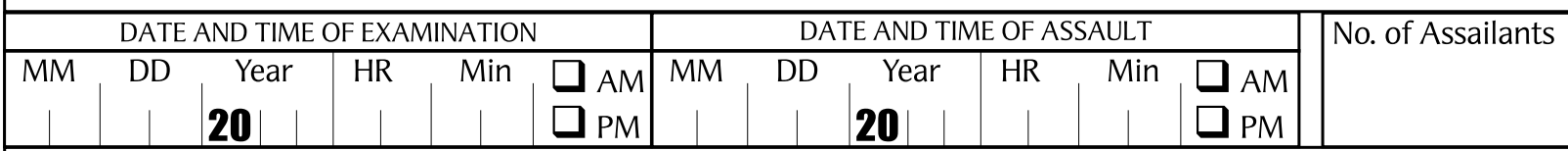

\begin{tabular}{ll} 
Alleged Assailants \\
$\square$ Unknown \\
\hline Known (indicate relation to victim)
\end{tabular}

Place Assault Occurred

Chief Complaints / Presenting Symptoms

Circumstances surrounding the incident (patient account) remember to record (penetration, how / where, what was used? struggle)

\begin{tabular}{|c|c|c|c|c|c|c|c|c|}
\hline \multirow{2}{*}{$\begin{array}{l}\text { Type of Assault } \\
\square \text { Oral } \\
\square \text { Vaginal } \\
\square \text { Anal } \\
\square \text { Other sex }\end{array}$} & \multicolumn{2}{|c|}{$\begin{array}{l}\text { Use of Condom? } \\
\square \text { Yes } \\
\square \text { No }\end{array}$} & \multicolumn{6}{|c|}{$\square$ No $\square$ Yes (indicate which station \& when) } \\
\hline & \multicolumn{5}{|c|}{$\begin{array}{l}\text { Attended a health facility before this one? } \\
\square \text { No } \square \text { Yes (indicate which one \& where) }\end{array}$} & \multicolumn{2}{|c|}{$\begin{array}{c}\text { Were you treated? } \\
\square \text { Yes } \\
\square \text { No }\end{array}$} & $\begin{array}{l}\text { Were you given } \\
\text { any notes? } \\
\square \text { Yes } \square \text { No }\end{array}$ \\
\hline \multicolumn{9}{|l|}{ Comments } \\
\hline \multicolumn{9}{|c|}{ Significant medical history / surgical } \\
\hline \begin{tabular}{l|l} 
OB / GYN & Parity \\
HISTORY &
\end{tabular} & & \multicolumn{2}{|c|}{ Contraception type } & LMP & \multicolumn{2}{|c|}{$\begin{array}{l}\text { Known Pregnancy? } \\
\square \text { Yes } \square \text { No }\end{array}$} & \multicolumn{2}{|c|}{$\begin{array}{l}\text { Date of last consentual sexual } \\
\text { intercourse }\end{array}$} \\
\hline \begin{tabular}{c|c} 
GENERAL & BP \\
CONDITION &
\end{tabular} & Temp & \begin{tabular}{l|l}
$\mathrm{RF}$ \\
$\mathrm{C}$
\end{tabular} & \multicolumn{2}{|c|}{\begin{tabular}{l|l} 
RR & Pulse Rate \\
\end{tabular}} & \multicolumn{4}{|c|}{ Demeanour (calm, looks age or not, etc) } \\
\hline $\begin{array}{l}\text { PSYCHOLOGICAL } \\
\text { ASSESSMENT }\end{array}$ & \multicolumn{8}{|c|}{$\begin{array}{l}\text { Mental state (normal, confused, flashback, hyper-aroused, } \\
\text { dazed, coma, retarded, extremely calm) }\end{array}$} \\
\hline \multirow{2}{*}{$\begin{array}{c}\text { Did the patient } \\
\text { change clothes? } \\
\square \text { Yes } \\
\square \text { No }\end{array}$} & \multicolumn{8}{|c|}{ State of clothes (stains, tears, colour, where were the worn clothes taken? } \\
\hline & \multicolumn{3}{|c|}{$\begin{array}{l}\text { Were the clothes put } \quad \square \text { Yes } \\
\text { in non-plastic paper bags? } \square \text { No }\end{array}$} & \multicolumn{3}{|c|}{$\begin{array}{l}\text { Were the clothes } \square \text { Yes } \\
\text { given to the police? } \square \text { No }\end{array}$} & \multicolumn{2}{|c|}{$\begin{array}{l}\text { Did the police sign rape } \\
\text { register at health facility? }\end{array}$} \\
\hline $\begin{array}{l}\text { Did the patient } \\
\text { have a bath? } \\
\square \text { Yes } \\
\square \text { No }\end{array}$ & $\begin{array}{l}\text { Did the patient } \\
\text { go to the Toilet } \\
\square \text { Long Call } \\
\square \text { Short Call }\end{array}$ & \multicolumn{7}{|c|}{$\begin{array}{l}\text { Does the survivor have any details on the assailant? (Is the assailant known, is there } \\
\text { any relation, did the assailant leave any marks on the assailant etc.?) } \square \text { Yes } \square \text { No } \\
\text { Comments }\end{array}$} \\
\hline
\end{tabular}


Genital Examination (of the patient / complainant - indicate discharges, inflammation, bleeding)

\begin{tabular}{l} 
Describe in detail the physical state of and any details (FEMALE): \\
Outer genitalia \\
\hline Vagina / hymen \\
\hline Cervix \\
\hline Describe in detail the physical state of and all details (MALE): \\
Outer genitalia \\
\hline Anus
\end{tabular}

Other significant orifices (oral cavity of tongue, palate, etc)

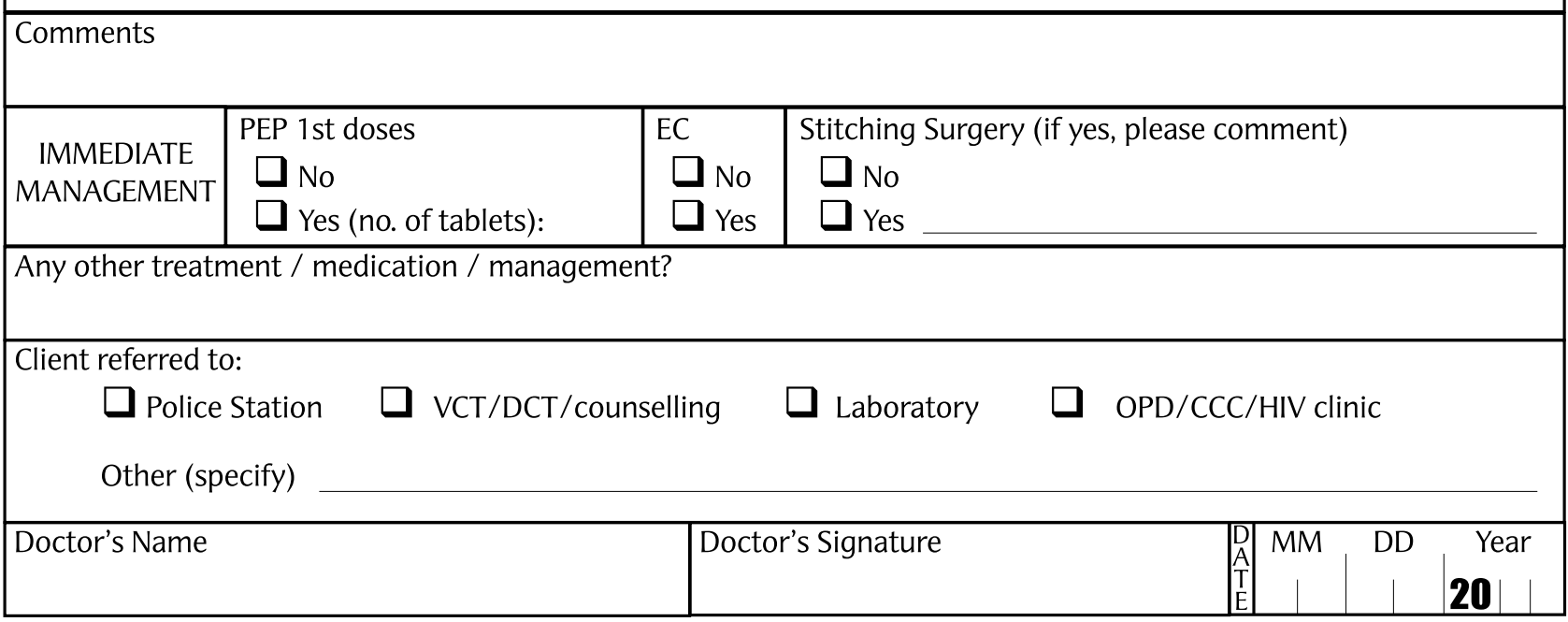

\begin{tabular}{|c|c|c|c|c|c|}
\hline \multirow{5}{*}{$\begin{array}{l}\mathbf{L} \\
\mathbf{A} \\
\mathbf{B} \\
\mathbf{0} \\
\mathbf{R} \\
\mathbf{A} \\
\mathbf{T}\end{array}$} & \multirow{2}{*}{ SAMPLE TYPE } & \multirow[t]{2}{*}{ TEST } & \multicolumn{2}{|c|}{ PLEASE TICK APPLICABLE } & \multirow[t]{2}{*}{ COMMENTS } \\
\hline & & & $\begin{array}{c}\text { National } \\
\text { Government } \\
\text { Lab }\end{array}$ & $\begin{array}{l}\text { Health } \\
\text { Facilty } \\
\text { Lab }\end{array}$ & \\
\hline & \multirow{3}{*}{$\begin{array}{c}\text { External } \\
\text { Vaginal } \\
\text { Swab }\end{array}$} & Sperm & & & \\
\hline & & DNA / CS & & & \\
\hline & & Other & & & \\
\hline \multirow{8}{*}{$\begin{array}{c}\text { S } \\
\text { A } \\
\text { M } \\
\text { P } \\
\text { L } \\
\text { E } \\
\text { S }\end{array}$} & $\begin{array}{l}\text { Internal (high) } \\
\text { Vaginal Swab }\end{array}$ & Sperm & & & \\
\hline & \multirow{3}{*}{ Urine } & $\mathrm{P} / \mathrm{T}$ & & & \\
\hline & & Microscopy & & & \\
\hline & & Other & & & \\
\hline & Anal Swab & & & & \\
\hline & Skin Swab & & & & \\
\hline & Blood & & & & \\
\hline & Other & & & & \\
\hline
\end{tabular}

CHAIN OF CUSTODY

\begin{tabular}{|c|c|c|c|c|c|c|c|c|}
\hline \multicolumn{9}{|c|}{ These/All/Some of the samples packed \& issued (please specify) } \\
\hline $\begin{array}{l}\mathbf{T} \\
\mathbf{0}\end{array}$ & $\begin{array}{l}\text { Examining Medical, clinical officer or Nurse } \\
\text { Name: }\end{array}$ & Signature & MM & DD & \begin{tabular}{l|} 
Year \\
$\mathbf{2 0}$
\end{tabular} & $\mathrm{HR}$ & Min & $\begin{array}{l}\square \text { AM } \\
\square \text { PM }\end{array}$ \\
\hline $\begin{array}{l}B \\
Y\end{array}$ & $\begin{array}{l}\text { Examining Medical, clinical officer or Nurse } \\
\text { Name: }\end{array}$ & Signature & MM & $\mathrm{DD}$ & $\begin{array}{l}\text { Year } \\
\mathbf{2 0}\end{array}$ & & Min & $\begin{array}{l}\square \mathrm{AM} \\
\square \mathrm{PM}\end{array}$ \\
\hline
\end{tabular}


Physical examination [indicate sites and nature of injuries, bruises and marks outside of the genitalia]

Please use the sketches below to indicate injuries, inflamations, marks on various body parts of the survivor

\section{Sketch of person}

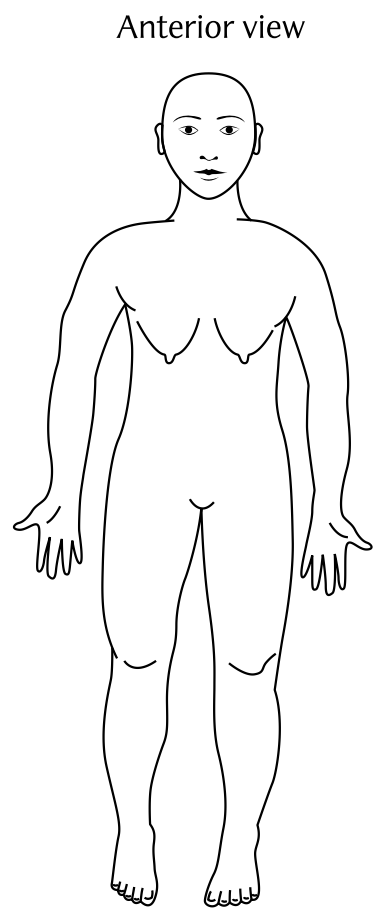

Posterior view
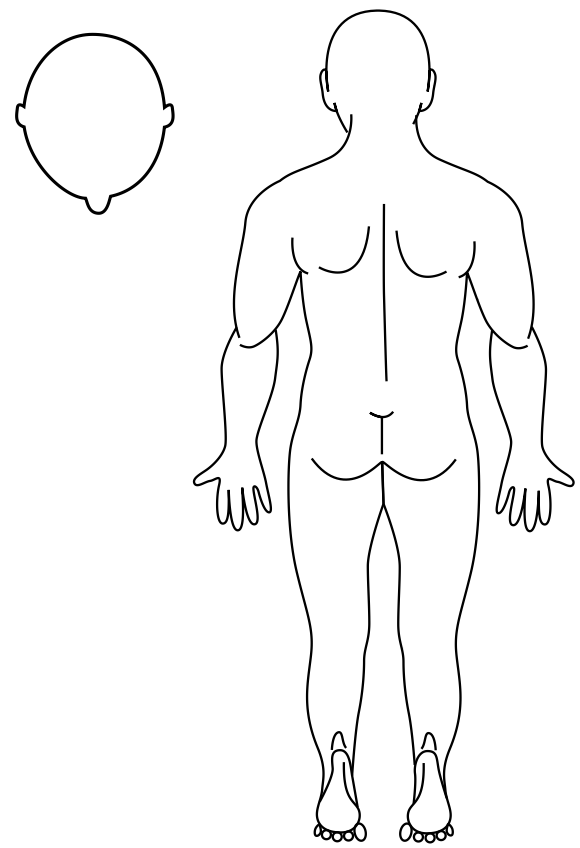

Comments

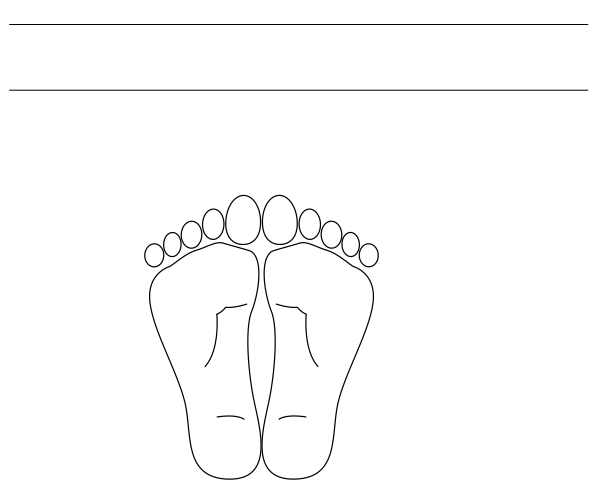

\section{Female Genitalia}

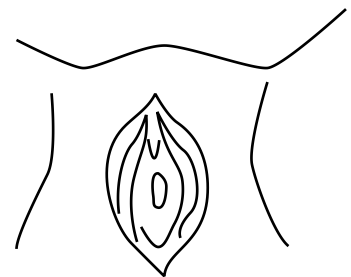

$+$

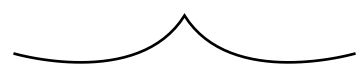

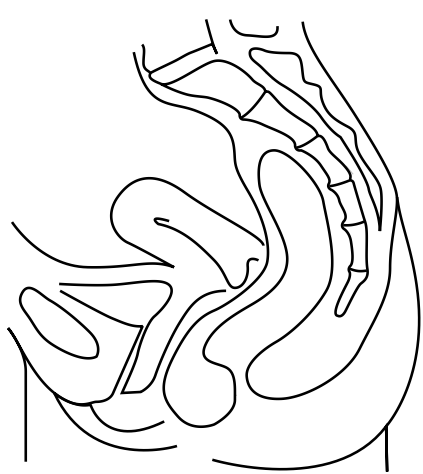
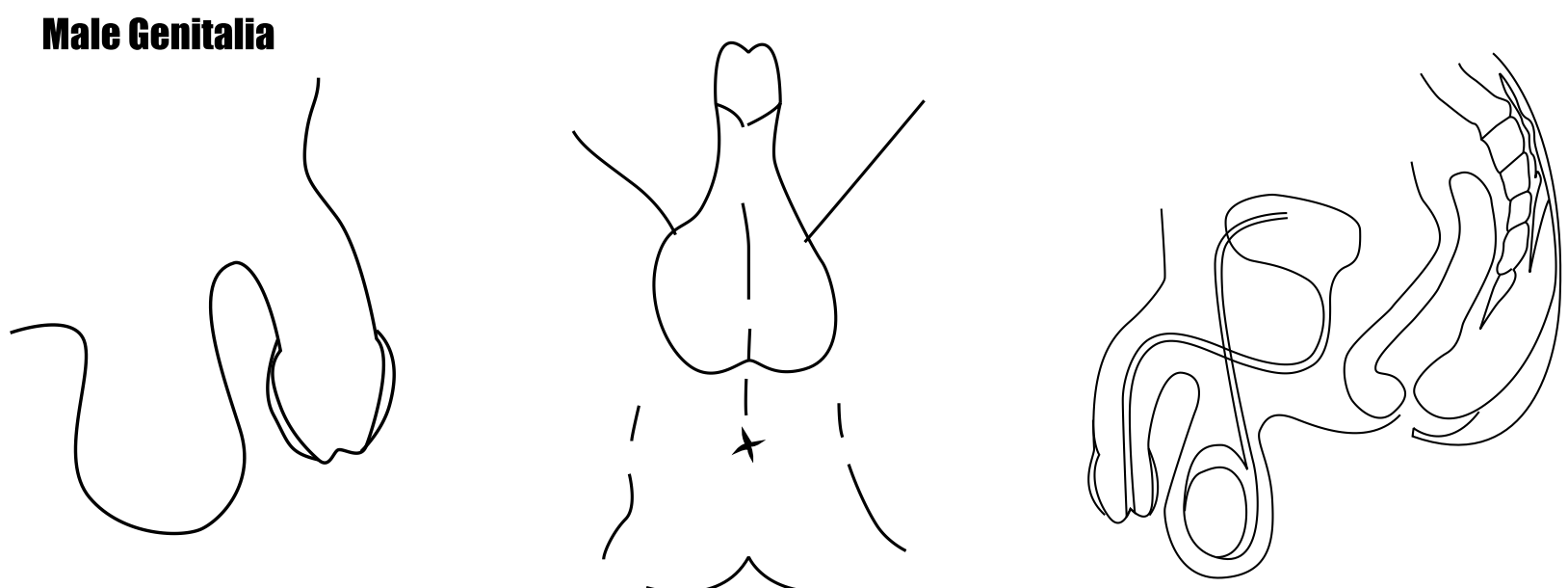


\section{REF ER E N CES}

i. Kenya, Ministry of Health, Division of Reproductive Health (2004) National Guidelines on Medical Management of Rape/Sexual Violence.

ii. American college of emergency physicians (n.d.). Evaluation and management of the sexually assaulted or sexually abused patient. http://www.acep.org/library/ pdf/sxa_handbook.pdf.Date accessed: 13/12/2006

iii. Du Mont \& Parnis (2006). The uses and impacts of medico-legal evidence in sexual assault cases: A global review.

iv. (Note iii Above)

V. World Health Organization (2003) Guidelines for Medico-Legal Care for Victims of Sexual Violence

vi. Ibid

vii. (Note iii Above)

viii. Krug EG et al., eds. (2002)World report on violence and health. Geneva, World Health Organization.

ix. Kenya, Sexual Offences Act,2006

X. Rape - the invisible crime. Http://web.amnesty.org/library/index/engafr320012002 Al Index: AFR 32/001/2002, Date accessed: 08/03/2008

Xi. The CRADLE (2002) Case Trends Monitor, The CRADLE-The Children Foundation, Nairobi, Kenya

Xii. Parris, D. et al (2002) 'Examining the Standardized Application of Rape Kits: An Exploratory Study of Post-Sexual Professional Practices.' Health Care for Women International ; 23(8):846-853

xiii. Odhiambo M (2003) Legal Hurdles in dealing with Rape. African Woman and Child Feature Service. www.awcfs.org. Date accessed: 20/2/2007

XiV. Mogeni, J. (2005) 'Sexual Violence: Developing a Culture of Accountability.' Sexuality in Africa Magazine, Vol.2 Issue 4.

XV. 'A medico-legal workshop(2003) on "Forensic medical examination, care \& treatment of rape survivors in Kenya", hosted by Amnesty International,\& Liverpool VCT, Kenya, Kenya Women Workers Organization and Kenya Medical Association.

xvi. (Note ix Above)

XVii. Kilonzo N, Taegtmeyer M, Molyneux S, Kibaru J, Kamonji V, Theobald S. Engendering health sector responses to sexual violence and HIV in Kenya: Results of a qualitative study. AIDS Care 2008;20: 188-90. PMID:18293127 doi:10.1080/09540120701473849

xviii. (Note xiv Above)

xix. (Note iii Above) 

